\title{
Geotechnique
}

\section{A microscale-based model for small-strain stiffness in unsaturated granular geomaterials \\ --Manuscript Draft--}

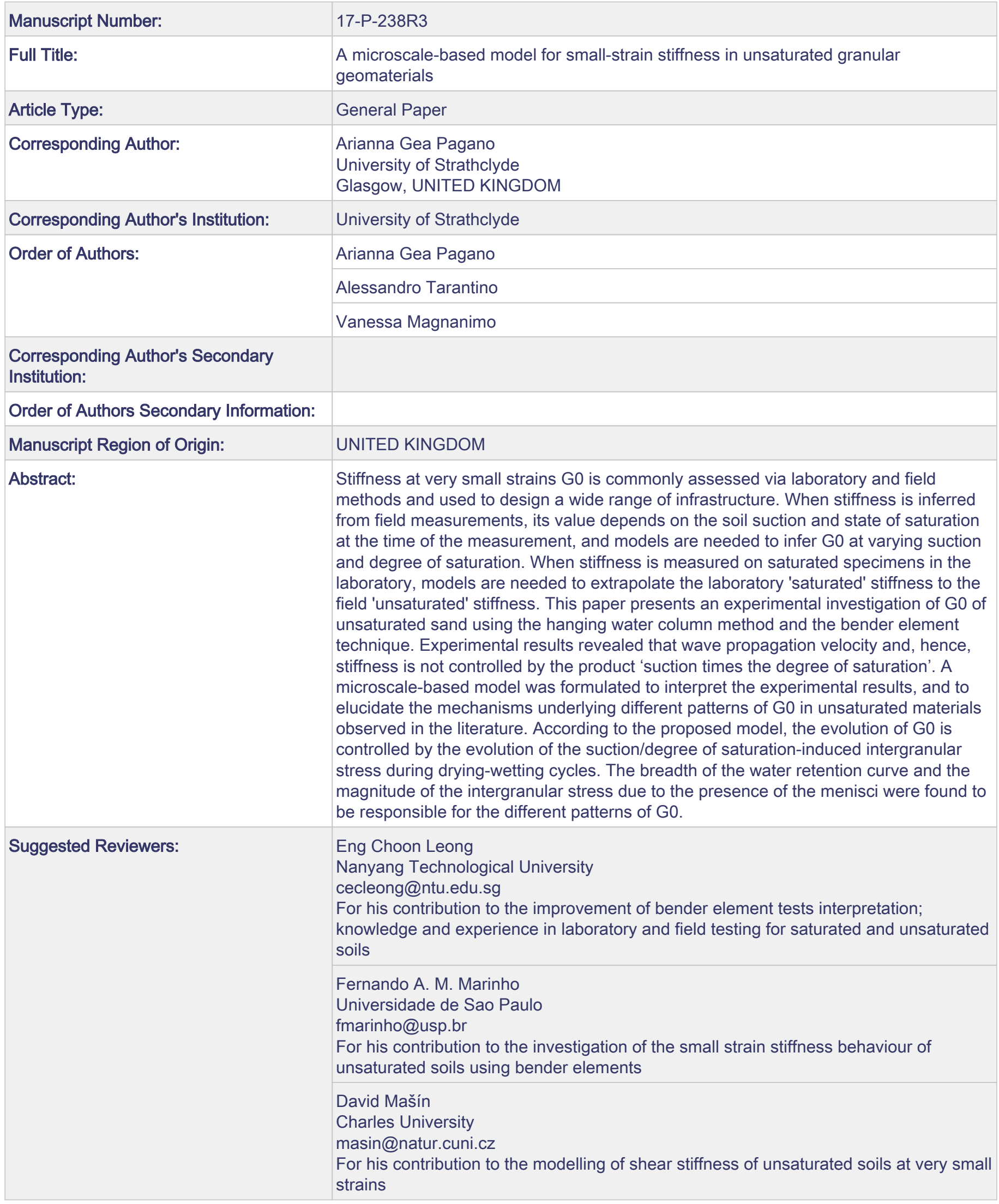


Opposed Reviewers:

Additional Information:

Question

Response

Please enter the total number of words in 6654

the main text only.

The main text of the paper should be as concise as possible. The word count of

General Papers should not exceed 5000

words and for Technical Notes should not exceed 2000 words.

The word count of a submission excludes the abstract, list of notation,

acknowledgements, references, tables and figure captions.

Discussions, Book Reviews, and

Obituaries should be less than 1000

words.

Whilst Geotechnique reserves the right to publish papers of any length Authors

should be aware that any submission for a General Paper that is significantly over the word limit will be subjected to preassessment and may be returned to the Authors for editing prior to being sent for review.

The word limit for Technical Notes will be strictly adhered to, and if over 2000

words, the submission will be considered as a General Paper.

Have you included a full notation list including definitions (and SI units of measurement where appropriate) for any mathematical terms and equations included in your paper?

Have you included a completed copyright Yes transfer form? This is required for all publications and can be found here. Further information is available here.

Have you uploaded each of your figures Yes separately and in high-resolution .tiff (ideal for photographs) or .eps files (best for line drawings)? This is required for all figures before your paper can be accepted. Our figure requirements can be found here.

Have you uploaded your tables in an editable Microsoft Word (.doc) format? 


\begin{tabular}{l|l|l|}
$\begin{array}{l}\text { Have you included a separate list of all } \\
\text { your figure and table captions? }\end{array}$ & Yes \\
\hline $\begin{array}{l}\text { Are your figures clear when printed in } \\
\text { black and white? (For example, are plot } \\
\text { lines distinguishable; are tints sequentially } \\
\text { graded?) As this journal is printed in black } \\
\text { and white, any figures that are unclear } \\
\text { may be removed. }\end{array}$ & Yes \\
\hline $\begin{array}{l}\text { Are your references in Harvard style? Our } \\
\text { reference guidelines can be found here. }\end{array}$ & Yes \\
\hline $\begin{array}{l}\text { To ensure your paper is indexed correctly } \\
\text { - and therefore as discoverable as } \\
\text { possible - in our ICE Virtual Library, } \\
\text { please choose up to } 6 \text { keywords from our } \\
\text { Keywords List. This can be found here. } \\
\text { We are unable to accept keywords that do } \\
\text { not appear on this list. }\end{array}$ & \\
\hline $\begin{array}{l}\text { Manuscript Classifications: } \\
\text { Author Comments: }\end{array}$ & & \\
\hline Bender elements; LABORATORY CHARACTERISATION AND SAMPLING OF SOILS; & SOILS MECHANICS \& CONSTITUTIVE MODELS; Stiffness; UNSATURATED SOILS \\
\hline
\end{tabular}


Glasgow, 10th August 2018

Craig Schaper

Journals Editor

Geotechnique

Subject: Submission of revised paper "A microscale-based model for small-strain stiffness in unsaturated granular geomaterials" - Article number: 17-P-238

Dear Mr. Schaper,

Thank you for your email dated 1st August 2018. We are pleased to know that the paper has been accepted for publication in Géotechnique.

The files specified in your email have been resubmitted at the required resolution. If there is still any problem with the resubmitted files, please do not hesitate to contact me.

Sincerely,

Dr Arianna Gea Pagano

University of Strathclyde 


\section{LIST OF CAPTIONS FOR FIGURES AND TABLES}

Figure 1. Grain size distribution of the soil specimen

Figure 2. Schematic layout of the laboratory equipment: a) triaxial cell with measurement and control of pore water pressure and cell pressure and b) modified top cap and base pedestal equipped with bender elements

Figure 3. Pluviator in closed and open position during specimen preparation

Figure 4. Average degree of saturation during first wetting, first drying, re-wetting, main drying and main wetting

Figure 5. Schematic view of the application of suction during a) drying path, and b) wetting path; c) hydraulic paths followed by points at different elevations in the specimen during drying and wetting paths.

Figure 6. WRCs for main drying, main wetting and scanning wetting paths using van Genuchten functions

Figure 7. Examples of corrected input and output signals

Figure 8. Small strain stiffness during hydraulic hysteresis

Figure 9.Schematic illustration of the proposed small strain stiffness model: from macroscopic intergranular stress to macroscopic stiffness

Figure 10. Unsaturated soil packing: a) idealised unsaturated soil; b) evolution of the intergranular stress in the meniscus water region and in the bulk water region with suction

Figure 11.Hertzian contact model

Figure 12.Idealised particle configuration: a) simple cubic (SC) and b) body centred cubic (BCC) 
Figure 13. a)Variation of G0 and upper and lower bounds of C1212 during drying-wetting cycle; schematic view of the values of suction and degree of saturation for the calculation of the bounding values of C1212 during b) main drying, and c) scanning wetting

Figure 14. Influence of the breadth of the water retention curve on the variation of G0 for soil A and B : a) water retention curves; b) variation of G0 with suction; c) variation of intergranular stress with suction

Figure 15. Influence of the meniscus intergranular stress on the variation of G0 for soil C and D : a) water retention curve; b) variation of G0 with suction; c) variation of intergranular stress with suction

Table 1. Physical properties of the soil specimen

Table 2. Physical properties of the silt filter

Table 3. Parameters of the water retention functions

Table 4. Model parameters kn0 and oim for SC and BCC configurations 


\section{LIST OF NOTATIONS}

$G_{0} \quad$ Small strain shear modulus $[\mathrm{kPa}, \mathrm{MPa}]$

$\sigma \quad$ Total stress $[\mathrm{kPa}]$

$u_{a} \quad$ Air pressure $[\mathrm{kPa}]$

$S_{r} \quad$ Degree of saturation

s

Suction $[\mathrm{kPa}]$

$P \quad$ Passing percentage [\%]

D Anticipated sieve size [mm]

$D_{100} \quad$ Sieve size corresponding to a passing percentage of $100 \%[\mathrm{~mm}]$

$D_{0} \quad$ Sieve size corresponding to a passing percentage of $0 \%[\mathrm{~mm}]$

$\theta \quad$ Volumetric water content

$\theta_{R} \quad$ Residual volumetric water content

$\theta_{0} \quad$ Saturated volumetric water content

$\alpha, n \quad$ van Genuchten fitting parameters

$V_{s} \quad$ Shear wave propagation velocity $[\mathrm{m} / \mathrm{s}]$

$L_{t t} \quad$ Tip-to-tip distance [m]

$t \quad$ Travel time [s] 


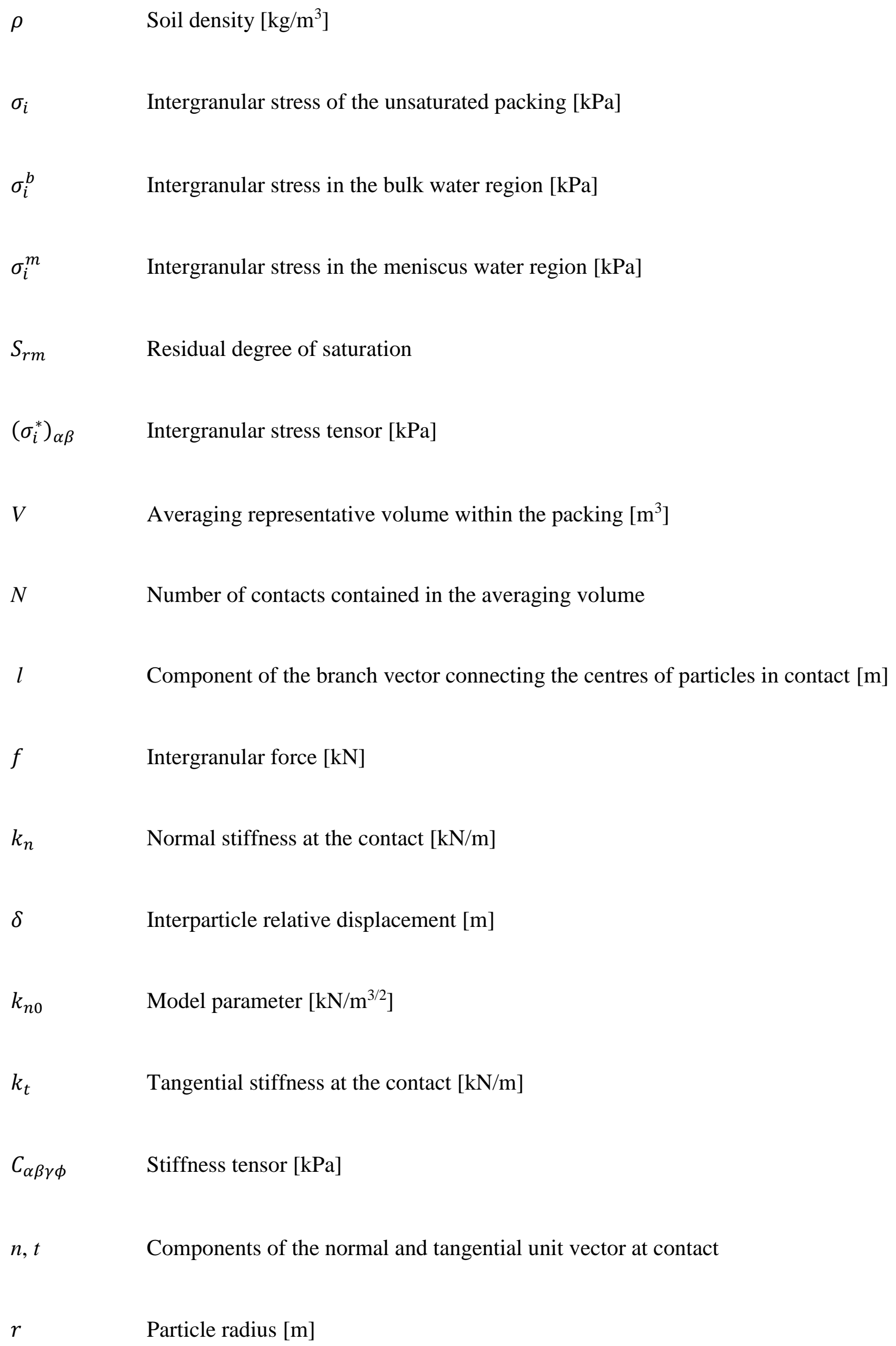




\title{
A microscale-based model for small-strain stiffness in
}

\section{unsaturated granular geomaterials}

\author{
Arianna Gea Pagano*, Alessandro Tarantino*, and Vanessa Magnanimo**
}

\author{
AFFILIATION: \\ * Department of Civil and Environmental Engineering, University of Strathclyde \\ ** Assistant Professor, Multiscale Mechanics Group, University of Twente
}

\section{ABSTRACT}

Stiffness at very small strains $G_{0}$ is commonly assessed via laboratory and field methods and used to design a wide range of infrastructure. When stiffness is inferred from field measurements, its value depends on the soil suction and state of saturation at the time of the measurement, and models are needed to infer $G_{0}$ at varying suction and degree of saturation. When stiffness is measured on saturated specimens in the laboratory, models are needed to extrapolate the laboratory 'saturated' stiffness to the field 'unsaturated' stiffness. This paper presents an experimental investigation of $G_{0}$ of unsaturated sand using the hanging water column method and the bender element technique. Experimental results revealed that wave propagation velocity and, hence, stiffness is not controlled by the product 'suction times the degree of saturation'. A microscale-based model was formulated to interpret the experimental results, and to elucidate the mechanisms underlying different patterns of $G_{0}$ in unsaturated materials observed in the literature. According to the proposed model, the evolution of $G_{0}$ is controlled by the evolution of the suction/degree of saturation-induced intergranular stress during dryingwetting cycles. The breadth of the water retention curve and the magnitude of the intergranular stress due to the presence of the menisci were found to be responsible for the different patterns of $G_{0}$ 


\section{INTRODUCTION}

The shear modulus of soil at very small strain levels (less than $0.001 \%$ ), typically denoted as $G_{0}$, is a stiffness parameter commonly assessed via laboratory and field methods. It is a fundamental parameter for a wide range of geotechnical problems and it is used for the prediction of soil response under both static and dynamic loading conditions. For shallow geotechnical infrastructure interacting with the atmosphere, the unsaturated condition of the soil should be taken into account in both the interpretation of field measurements and the selection of design parameters. When stiffness is inferred from field measurements involving shallow unsaturated layers, its value depends on the state of saturation at the time of the measurement. Since the state of saturation may change over time, the variation of stiffness with the degree of saturation should be predicted in order to analyse the geotechnical structure over a realistic range of scenarios. On the other hand, when stiffness is inferred from laboratory measurements on saturated specimens, models are needed to extrapolate the 'saturated' laboratory stiffness to the 'unsaturated' stiffness in the field.

For the case of small-strain stiffness of soil in saturated state, a large number of models have been proposed over the past decades. The effect of variables such as confining stress, void ratio, overconsolidation ratio, and strain rate have been widely investigated (Hardin \& Richart, 1963; Hardin \& Black, 1968; Hardin \& Drnevich, 1972; Hardin, 1978; Iwasaki, et al., 1978; Viggiani \& Atkinson, 1995a; Stokoe, et al., 1995; Rampello, et al., 1997; Sorensen, et al., 2010). Under saturated conditions, $G_{0}$ is usually fitted by empirical power functions of the aforementioned variables.

For the case of small-strain stiffness of soils in unsaturated state, a number of models have recently been proposed to quantify $G_{0}$ over a wide range of degrees of saturation (Mancuso, et al., 2002; Mendoza, et al., 2005; Ng, et al., 2009; Sawangsuriya, et al., 2009; Khosravi \& 
McCartney, 2012; Oh \& Vanapalli, 2014; Wong, et al., 2014; Dong \& Lu, 2016). $G_{0}$ is recognised to be affected by both suction and degree of saturation, which may vary independently because of the hydraulic hysteresis and the dependency of the void-ratio on the water retention behaviour. A key question is how these two variables control the small-strain stiffness and whether they can be combined into a single variable.

A common approach adopted by several authors (Sawangsuriya, et al., 2009; Khosravi \& McCartney, 2012; Oh \& Vanapalli, 2014) is to derive empirical or semi-empirical relationships for $G_{0}$ using the product between suction and degree of saturation as a stress variable (Jommi, 2000), often referred to as Bishop's effective stress for unsaturated soils:

$\sigma^{\prime \prime}=\sigma-u_{a}+S_{r} \cdot s$

where $\sigma$ is the total stress, $s$ is the suction, and $S_{r}$ is the degree of saturation. An implicit assumption in this approach is that, at the same suction, the product $S_{r} \cdot s$ increases with an increase in degree of saturation. Since the degree of saturation along a drying path is higher than the degree of saturation along a wetting path, one would expect $G_{0}$ to be higher along a drying path. Although an evidence of this has been observed experimentally (Khosravi, et al., 2016), a number of experimental investigations show an opposite trend, i.e. the soil is observed to be significantly stiffer along a wetting path (Khosravi \& McCartney, 2011; Ng, et al., 2009; Ng \& $\mathrm{Xu}, 2012)$.

Inspection of experimental data also reveals that the change of $G_{0}$ with suction or degree of saturation occurs in either a monotonic or non-monotonic fashion. Qian et al. (1993) showed the effect of degree of saturation on $G_{0}$ of unsaturated sand specimens tested from a dry condition to complete saturation (wetting path only) in a resonant column apparatus, obtaining a nonmonotonic variation of $G_{0}$ with degree of saturation. Similar results have been confirmed by 
other researchers (Marinho, et al., 1995; Senthilmurugan \& Ilamparuthi, 2005; Weidinger, et al., 2009). Data presented by Khosravi et al. (2016) seem to suggest that this type of response is linked to the stiffness behaviour along a water retention hysteresis loop. When $G_{0}$ increases monotonically with suction, stiffness appears to be higher along a wetting path. When $G_{0}$ varies non-monotonically with suction, stiffness appears to be lower along a wetting path. Ideally, a stiffness model should be capable of capturing the interplay between these two aspects. However, no models presented so far are capable of addressing this coupling.

This paper first presents an experimental investigation of the independent effect of suction and degree of saturation on $G_{0}$ along a full hydraulic hysteresis loop. An unsaturated sand specimen was tested in a modified triaxial cell apparatus equipped with bender elements using the hanging water column method. Then, a simple macroscopic model informed by existing micro-mechanical models is proposed in order to interpret and predict the evolution of $G_{0}$ during hydraulic hysteresis. The proposed model is then challenged to elucidate a range of different responses observed in the literature.

\section{MATERIALS AND METHODS}

\section{1. $\quad$ Testing materials}

A well-graded sand obtained by mixing different fine, medium and coarse grained sands was used in this study. The mixture was prepared according to a modified Fuller equation:

$P=\frac{\sqrt{\frac{D}{D_{100}}}-\sqrt{\frac{D_{0}}{D_{100}}}}{1-\sqrt{\frac{D_{0}}{D_{100}}}} \times 100$

where $P$ is the passing percentage, $D$ is the anticipated sieve size, and $D_{100}$ and $D_{0}$ are the sieve sizes corresponding to a passing percentage of $100 \%$ and $0 \%$ respectively. Figure 1 shows 
the grain-size distribution (GSD) of the tested specimen. The well-graded GSD allowed the desaturation process to be gradual, resulting in a smooth water retention curve. Hence, differences in the degree of saturation between the top and the bottom of the specimen could be minimised. The physical properties of the soil specimen are shown in Table 1.

The high air-entry filter at the bottom of the specimen was prepared using a silty, crushed quartz stone known by the commercial name of Silica (mean particle size of $25.2 \mu \mathrm{m}$ ). The physical properties of the filter are summarized in Table 2.

\subsection{Laboratory equipment}

A triaxial test apparatus was modified for testing soil specimens under saturated and unsaturated conditions, and for measuring the velocity of propagation of mechanical shear waves (bender element technique). A schematic layout of the equipment is shown in Figure 2.

The specimen was tested along a full hydraulic hysteresis loop under constant isotropic confining stress. Cell pressure was controlled via a device that allows the water pressure in the cell to be maintained while also measuring the water volume changes occurring in the cell (P/V controller 1 in Figure 2a). Pore-water pressure inside the specimen was controlled and measured in two different ways depending on whether the specimen was tested under saturated or quasisaturated/unsaturated conditions.

In the former case, the base pedestal was connected to a second pressure/volume controller device (P/V controller 2 in Figure 2a) used to impose the pore-water pressure. In the latter case, the base pedestal was connected to a height-adjustable water reservoir, with the water mass exchanged with the specimen continuously monitored using a balance (Figure 2a). Positive/negative pore-water pressure was imposed by adjusting the height of the reservoir. Water evaporation from the reservoir was determined by monitoring an identical reservoir placed on a second balance. 
The top cap and base pedestal were modified to accommodate a pair of specially manufactured double-layered piezoelectric transducers for transmission and measurement of shear waves (bender element technique, Shirley \& Hampton, 1978). A detailed scheme of the top cap and pedestal is shown in Figure 2b. A computer-controlled function generator and oscilloscope allowed the input signal to be sent and both input and output signals to be recorded respectively. Two types of piezoceramic elements were used for the construction of the sensors: a BIMS-N-PZT5A4-HT x-poled element (used as a receiver) and a BIMP-N-PZT5A4-HT ypoled element (used as a source) by Morgan Technical Ceramics. The series-type bender element was shielded with conductive paint and grounded in order to prevent crosstalk effects (Lee \& Santamarina, 2005).

\section{3. $\quad$ Testing procedure}

\section{Stage 1 - High air-entry filter preparation}

The high air-entry filter was formed on the pedestal by consolidating a silt layer. The silt layer allows the transmission of suction to the specimen while preventing the ingress of air into the hydraulic system. Furthermore, it prevents the development of large pores at the specimen/filter interface which is likely to occur in coarse-grained materials.

A filter paper disc was first placed on the base pedestal and a latex membrane was placed around the pedestal and fixed with O-rings. A split mould was assembled around the pedestal, the membrane stretched to the top of the mould and held open by applying a small vacuum. A silt slurry (water content $\mathrm{w}=500 \%$ ) was then gently poured into the mould and allowed to settle for 48 hours. Excess clear water was then drained out by connecting the hydraulic drainage to the reservoir (valve B closed, valve A open in Figure $2 a$ ) and adjusting the reservoir height until its water level was 1-2 millimetres above the top of the silt surface. 
The filter was consolidated by applying suction via the hanging water column method. The water reservoir was lowered in steps, inducing a water flow from the silt filter to the reservoir. The filter remained saturated during this stage. The pore-water pressure in the filter was then raised back to zero suction by raising the water level up to the top of the filter.

\section{Stage 2 - Specimen preparation}

Once the silt filter had been consolidated, the sand specimen was prepared. The material was oven-dried, mixed and placed into a purposely manufactured pluviator (Figure 3) to obtain a specimen with level top surface. During pluviation, the drainage channels were kept open (valve B closed, valve A open in Figure 2a) to prevent desaturation of the silt filter (i.e. water uptake by the specimen due to capillarity). Water uptake occurring during pluviation was continuously monitored by recording any water exchanges between the specimen and the water reservoir using the balance. This allowed the degree of saturation of the specimen to always be known. After pluviation, the top cap was placed on top of the specimen after interposing a filter paper.

\section{Stage 3 - First wetting and first drying}

A first wetting path was performed by raising the reservoir slightly above the top of the specimen. The corresponding mass of exchanged water at equilibrium was used to calculate the degree of saturation of the specimen, which reached a value of 0.85 . With the split mould still in place, the reservoir was lowered in steps (first drying) to make the specimen able to self-stand and to allow grain rearrangements to take place when the height of the specimen could still be measured directly. The water exchange was continuously monitored and the degree of saturation was calculated at equilibrium for each step. The split mould was then removed and the triaxial cell was assembled and filled with de-aired water. A cell pressure of $10 \mathrm{kPa}$ was then applied through the P/V controller (valve C open in Figure 2a).

\section{Stage 4 - Re-wetting and back pressure application}


The specimen was re-saturated by raising the water reservoir up above the top of the specimen. As for the first wetting path, the degree of saturation at the end of this stage didn't reach unity. Hence, a full saturation procedure was performed in order to reach a higher degree of saturation $\left(S_{r}>0.95\right)$. The base pedestal was connected to the second P/V controller (valve B open, valve A closed in Figure 2a) to apply step-by-step increments of pore-water pressure (back pressure) to the specimen. During this stage, cell pressure was increased accordingly in order to keep the effective stress of the specimen constantly equal to $10 \mathrm{kPa}$. Full saturation was considered to be achieved when the change in pore-water pressure under undrained conditions associated with change in cell pressure was greater than 0.98 of the change in cell pressure $(B=0.98)$.

\section{Stage 5 - Drying and wetting cycle with wave velocity measurements}

The base pedestal was then reconnected to the water reservoir (valve B closed, valve A open in Figure $2 a$ ), and the hanging water column method was adopted to apply suction to the specimen and perform drying-wetting cycles. With valve D open, the reservoir was lowered/raised in steps inducing a specimen-to-reservoir/reservoir-to-specimen water flow. The degree of saturation was calculated at each step. Enough time was allowed for the pore-water within the specimen to reach hydraulic equilibrium with the water in the reservoir, ranging from 30 to 2500 minutes. Once equilibrium was reached for each suction step, a shear wave was triggered and recorded using the function generator and the oscilloscope.

\section{Stage 6 - Specimen last de-saturation and cell dismantling}

At the end of the test, the specimen was de-saturated in a single step to make it self-standing. The cell was emptied and dismantled, and the specimen's final height, diameter and water content were measured. 


\section{EXPERIMENTAL RESULTS}

\subsection{Water retention characteristics of the soil specimen}

Figure 4 shows the relationship between the average degree of saturation and the height of the reservoir (intended as the distance between the top of the specimen and the level of water in the reservoir) during first wetting and first drying (cell pressure equal to zero), re-wetting (cell pressure equal to $10 \mathrm{kPa}$ ), full saturation (varying cell pressure), and final drying-wetting cycle (cell pressure equal to $10 \mathrm{kPa}$ ). The degree of saturation at the end of the saturation procedure (i.e. at the beginning of the drying-wetting cycle, point D) was back calculated from the water content taken at the end of the test and was found to be equal to 0.96 . The data points associated with the first drying $(\mathrm{AB})$ and main drying $(\mathrm{DE})$ appear to lead to a similar air-entry value. This implicitly suggests that negligible deformation occurred upon the first drying path.

The experimental data are shown in Figure 4 in terms of the average degree of saturation, calculated from the measured overall mass of water within the specimen. However, suction and degree of saturation vary along the height of the specimen $(12.5 \mathrm{~cm})$. A difference in suction of $1.22 \mathrm{kPa}$ exists between the top and the bottom of the specimen and this may correspond to a significant difference in degree of saturation.

In order to derive the water retention behaviour more accurately, an approach similar to the one adopted by Stanier \& Tarantino (2013) was followed. The water behaviour was modelled by fitting the water exchanges over the height of the specimen rather than considering the average values of suction and degree of saturation. This approach is described in detail below.

Let us consider the schematic view of the specimen in Figure 5a. When lowering the reservoir from position 1 to 2 (drying path), points A, B, C and D at different heights within the specimen are all de-saturating from a saturated state. Therefore, they all move along a main drying curve, and reach different degrees of saturation at equilibrium (Points $\mathrm{A}_{2}$ to $\mathrm{D}_{2}$ in Figure 
$5 c$ ). When raising the reservoir from position 2 to 3 (Figure $5 b$ ), points $\mathrm{A}, \mathrm{B}, \mathrm{C}$ and D will resaturate from the different states of saturation that they reached after main drying. Therefore, they will move along different scanning wetting curves (points $\mathrm{A}_{3}$ to $\mathrm{D}_{3}$ in Figure $5 c$ ).

To model the water retention behaviour, van Genuchten-type functions (van Genuchten, 1980) were considered for the drying path and the scanning wetting paths. In turn, the function used to model a scanning path was assumed to be derived from the main wetting path by 'scaling' the main wetting curve via a fictitious residual volumetric water content. The following functions were considered:

Main drying: $\theta^{d}=\theta_{R}^{d}+\frac{\theta_{0}^{d}-\theta_{R}^{d}}{\left[1+\left(\alpha^{d} \cdot s\right)^{n^{d}}\right]^{m^{d}}}$

Main wetting: $\quad \theta^{w}=\theta_{R}^{w}+\frac{\theta_{0}^{w}-\theta_{R}^{w}}{\left\{1+\left[\alpha^{w} \cdot\left(s-s^{*}\right)\right]^{n^{w}}\right\}^{m^{w}}}$

Scanning wetting: $\quad \theta^{s c}=\theta_{R}^{s c}+\frac{\theta_{0}^{w}-\theta_{R}^{s c}}{\left\{1+\left[\alpha^{w} \cdot\left(s-s^{*}\right)\right]^{n^{w}}\right\}^{m^{w}}}$

where $\theta$ is the (volumetric) water content, $\theta_{R}$ is the residual water content, $\theta_{0}$ is the water content at suction lower than or equal to zero (pore-water pressure greater than or equal to zero), $s$ is the suction, $\alpha$ and $n$ are fitting parameters (with $m=1-1 / n$ ), and the superscripts $d, w$ and $s c$ refer to main drying, main wetting and scanning wetting path respectively.

For the main drying curve, the water content $\theta_{0}^{d}$ was derived from the water content measured experimentally at the positive pore-water pressure (back-pressure) of $500 \mathrm{kPa}$. The parameters $\alpha^{d}, n^{d}$ and $\theta_{R}^{d}$ were derived by matching the overall volume of water measured at each suction step upon the drying path with the integral of the main drying retention function (Equation 3) over the height of the specimen (a hydrostatic distribution of suction was assumed at equilibrium). 
For the main wetting curve, the water contents $\theta_{R}^{w}$ and $\theta_{0}^{w}$ were assumed to be equal to the ones associated with the main drying path $\left(\theta_{R}^{d} \equiv \theta_{R}^{w}\right.$ and $\left.\theta_{0}^{d} \equiv \theta_{0}^{w}\right)$. Since the experimental data in Figure 4 showed an average degree of saturation slightly lower than unity when the reservoir was level with the top surface of the specimen even after applying a back pressure, an additional parameter $s^{*}$ was introduced in the van Genuchten equation representing the value of negative suction leading to the water content $\theta_{0}^{w}$.

For the scanning wetting curves, the fictitious residual water content $\theta_{R}^{S c}$ used to scale the scanning wetting curve was derived by imposing that the scanning curve intersects the main drying curve at the value of suction at the end of the drying path (level 2 in Figure 5a-b):

$\theta_{R}^{S C}=\frac{\theta_{R}^{d}+\frac{\theta_{0}^{d}-\theta_{R}^{d}}{\left[1+\left(\alpha^{d} \cdot s\right)^{n^{d}}\right]^{m^{d}}}-\frac{\theta_{0}^{w}}{\left\{1+\left[\alpha^{w} \cdot\left(s-s^{*}\right)\right]^{n^{w}}\right\}^{m^{w}}}}{1-\left\{1+\left[\alpha^{w} \cdot\left(s-s^{*}\right)\right]^{n^{w}}\right\}^{m^{w}}}$

The specimen was divided into four slices (Figure 5a-b), each slice following a different scanning path. The parameters $\mathrm{s}^{*}, \alpha^{w}$, and $n^{w}$ were derived by matching the overall volume of water measured at each suction step along the wetting path with the integral of the four scanning retention functions over the height of the slice (Equation 5). The main drying, main wetting and scanning wetting curves derived from this best-fitting using the least-square method are shown in Figure 6, and the corresponding fitting parameters are reported in Table 3. For comparison, the experimental data in terms of the suction at the mid-height of the specimen and the average degree of saturation are also shown in the figure.

\subsection{Wave propagation results and interpretation}

An input sinusoidal signal with a frequency of $5 \mathrm{kHz}$ was triggered via the transmitter bender element at each suction step. The selected input frequency allowed the output signal to be detected easily during the whole test. The sinusoidal waveform was selected as it was observed 
to cause smaller ambiguity in arrival time than other types of waveform (Blewett, et al., 2000; Leong, et al., 2005; Viana da Fonseca, et al., 2009).

Figure 7 shows the input signal and some of the output signals recorded during the test. Each raw output signal was subject to filtering (Butterworth, low pass filter of order 1) and base-line correction prior to travel time interpretation, in order to remove the undesired effect of background noise without affecting the signal characteristics. The velocity of propagation of the shear wave $V_{S}$ through the specimen was then calculated as:

$V_{s}=\frac{L_{t t}}{t}$

where $L_{t t}$ is the travel length, and $t$ is the travel time of the wave. The value of $V_{s}$ for each suction step was calculated as the average of three measurements. The difference between the minimum and maximum shear-wave velocities in the triplicate measurement was found to be less than $1.5 \%$ of the average value.

The travel length $L_{t t}$ was taken as the tip-to-tip distance between source and receiver bender elements (Dyvik \& Madshus, 1985; Viggiani \& Atkinson, 1995a, Fernandez, 2000). Since the cell pressure was kept constant during the drying-wetting cycles, volume changes occurring in the cell and measured by the P/V controller 1 (Figure $2 a$ ) could be attributed to changes in the volume of the specimen. Under the assumption of isotropic behaviour, the axial deformation and, hence, the tip-to-tip distance could be inferred from the volume change. The total axial deformation was found to be less than $0.37 \%$ of the specimen height, resulting in a maximum error on the shear-wave velocity $\Delta V_{\mathrm{s}}= \pm 0.35 \mathrm{~m} / \mathrm{s}$, which was assumed to be negligible.

The determination of the travel time is more controversial. Although many researchers have proposed different approaches for travel time interpretation (Dyvik \& Madshus, 1985; Viggiani \& Atkinson, 1995a; Viggiani \& Atkinson, 1995b; Jovicic \& Coop, 1997; Santamarina \& Fam, 1997), there is still no agreement about the most reliable method. In this study, the travel time 
was chosen as the time interval between the first main peaks of the input and output signals, which is a simple alternative to more complex methods such as cross-correlation or cross-power of the transmitter and receiver signals (Viggiani \& Atkinson, 1995a). Although the resulting absolute values of $V_{\mathrm{s}}$ might be slightly less accurate, changes in stiffness during the test can be determined accurately as long as the choice of the arrival time is consistent throughout the analysis of the data (Viggiani \& Atkinson, 1995b).

\subsection{Small-strain stiffness calculation}

Interpretation of bender element tests is based on the assumption that the soil behaves as a linear elastic material at very small strain. The shear modulus can then be determined as:

$G_{0}=\rho V_{s}^{2}$

where $\rho$ is the soil density. Figure 8 shows the evolution of $G_{0}$ with the height of the reservoir. It appears that $G_{0}$ increases significantly with suction, and the soil appears to be stiffer upon a wetting path rather than a drying path.

\section{MICROSCALE-BASED MODEL FOR $\mathrm{G}_{0}$ IN UNSATURATED SOILS}

The approach followed in this paper to model the independent effect of suction and degree of saturation on the small-strain shear modulus $G_{0}$ consists of linking $G_{0}$ to an unsaturated intergranular stress $\sigma_{i}$, which depends in turn on both suction and degree of saturation. The intergranular stress is derived from equilibrium considerations at the particle-scale by assuming that water at the inter-particle contacts is present in the form of either bulk or meniscus water. The functional form that links the small-strain shear modulus to the intergranular stress is then derived on the basis of simplified micro-mechanical models. The different steps to derive $G_{0}$ as a function of $\sigma_{i}$ are schematically illustrated in Figure 9. 


\section{Macroscopic intergranular stress of unsaturated packings}

The degree of saturation/suction-induced intergranular stress, $\sigma_{i}$, may be formulated by considering an idealised packing of equal spheres in an ordered structure. Let us consider the idealised unsaturated packing as shown in Figure 10, and let us assume that the contact area of each pair of spherical particles is a point. The two-phase fluid can be described as the coexistence of a region fully occupied by bulk water (saturated region) and a region occupied by the menisci alone. Boso et al. (2005) derived an expression of the intergranular stress $\sigma_{i}$ of the unsaturated packing as:

$\sigma_{i}=\sigma+\left[\sigma_{i}^{b} \frac{S_{r}-S_{r m}}{1-S_{r m}}+\sigma_{i}^{m}\left(1-\frac{S_{r}-S_{r m}}{1-S_{r m}}\right)\right]$

where $S_{r}$ is the total degree of saturation, $S_{r m}$ is the residual degree of saturation (degree of saturation of the region occupied by the menisci alone), $\sigma$ is the total stress, $\sigma_{i}^{b}$ is the intergranular stress in the bulk water region, and $\sigma_{i}^{m}$ is the intergranular stress in the meniscus water region.

The first term in square brackets takes into account the contribution of suction to the intergranular stress in the saturated region, which is directly proportional to the suction (as $\sigma_{i}^{b} \equiv$ $s)$. The second term in square brackets indicates the contribution of suction to the intergranular stress in the meniscus water region. The two contributions of suction in Equation 9 are weighed by functions of the degree of saturation based on the assumptions that i) the areal degree of saturation equals the volumetric degree of saturation and ii) the variation of the volume occupied by the meniscus with suction can be neglected.

To explore the nature of the intergranular stress at the meniscus contact, it is convenient to examine the case of two rigid spherical particles with point contact. According to Fisher (1926), $\sigma_{i}^{m}$ is given by: 
$\sigma_{i}^{m}=\frac{\frac{2 \pi r T}{1+\tan (\theta / 2)}}{\pi r^{2}}$

where $\theta$ is the angle defining the position of the meniscus junction, $r$ is the particle radius, and $T$ is the surface tension. The angle $\theta$ is related to suction according to the following equation:

$s=T\left[\frac{1}{r\left(\frac{1}{\cos \theta}-1\right)}-\frac{1}{r\left(1+\tan \theta-\frac{1}{\cos \theta}\right)}\right]$

By combining Equation 10 and Equation 11, the relationship between the suction $s$ and the intergranular stress $\sigma_{i}^{m}$ in the meniscus water region can be derived. Figure $10 \mathrm{~b}$ shows the variation of $\sigma_{i}^{m}$ with suction for the case of $T=0.072 \mathrm{~N} / \mathrm{m}$ and $r=0.1 \mathrm{~mm}$, with $\theta$ ranging from $53^{\circ}$ (roughly corresponding to zero suction) to $22^{\circ}$. For the purpose of comparison, the bulk water intergranular stress $\sigma_{i}^{b}$ is also plotted. It can be seen that $\sigma_{i}^{m}$ can be assumed practically independent of suction.

Accordingly, the assumption made in the proposed model is that $\sigma_{i}^{m}$ is independent of suction even for the case of real, non-spherical particles. In this case, however, the value of $\sigma_{i}^{m}$ cannot be derived using Equation 10 but has to be calibrated experimentally as described later on in the paper.

\section{Micro-mechanical model: from macroscopic intergranular stress to microscopic intergranular force and stiffness}

In order to derive the functional form linking the macroscopic intergranular stress $\sigma_{i}$ in Equation 9 to the shear modulus $G_{0}$ a micro-mechanical model was used, based on the implicit assumption that the pore- fluid is homogenous and at zero pressure (e.g. air). Existing micro-mechanical models allow to derive general expressions of the macroscopic intergranular stress tensor, $\left(\sigma_{i}^{*}\right)_{\alpha \beta}$, of an idealised packing of discrete particles as a function of the microscopic 
intergranular force $f$ developing at each particle contact, using different averaging techniques (e.g. Liao \& Chang, 1997; Kruyt \& Rothenburg, 1998; Kruyt \& Rothenburg, 2001). Using the particle-in-volume averaging method, the following expression can be derived (Luding, 2004; Luding, 2005):

$\left(\sigma_{i}^{*}\right)_{\alpha \beta}=\frac{1}{V} \sum_{p \in V} \sum_{c=1}^{N} l_{\alpha}^{c} f_{\beta}^{c}$

where $V$ is an averaging representative volume within the packing, $N$ is the number of contacts contained in the averaging volume, $l$ is the component of the branch vector connecting the centres of particles in contact, the apex $c$ indicates the single contacts within $V, p$ is the generic particle occurring within $V$, and $\alpha, \beta$ are subscripts that indicate the combinations of the vertical and horizontal directions. In this study, only the normal component of the intergranular stress tensor was considered, i.e. $\left(\sigma_{i}^{*}\right)_{\alpha \alpha}=\sigma_{i}^{*}$ :

$\sigma_{i}^{*}=\frac{1}{V} \sum_{p \in V} \sum_{c=1}^{N} l^{c} f^{c}$

where $f$ is intended as the normal component of the force between two particles in contact. In turn, the force $f$ can be derived as a function of the normal stiffness at the contact, $k_{n}$, and the relative displacement in the normal direction, $\delta$ :

$f=f\left(k_{n}, \delta\right)$

Following the Hertzian contact model (Figure 11), the force $f$ can be derived as a non-linear function of $\delta$ (Love, 1927):

$f=k_{n 0} \delta^{3 / 2}$ 
where $k_{n 0}$ is a material constant depending on the characteristics of individual particles. In this study, $k_{n 0}$ is a model parameter determined experimentally as discussed later on in the paper.

Using Equation 15 the incremental stiffness $k_{n}$ can be written in terms of the force $f$ and the model parameter $k_{n 0}$ as:

$k_{n}=\frac{\partial f}{\partial \delta}=\frac{3}{2} k_{n 0} \delta^{1 / 2}=\frac{3}{2} k_{n 0}^{2 / 3} f^{1 / 3}$

In order to calculate the shear modulus of the packing (as described in the following paragraph), a tangential stiffness at the contact $k_{t}$ was also introduced. For the sake of simplicity, the tangential stiffness $k_{t}$ was assumed to be equal to a fraction of the normal stiffness $k_{n}$ : $k_{t}=\frac{2}{7} k_{n}$

\section{Micro-mechanical model: from microscopic stiffness to macroscopic stiffness}

The simplest approach to derive the macroscopic stiffness of idealised aggregates of identical, randomly distributed spherical particles is based on the mean-field theory (e.g. Digby, 1981; Walton, 1987). The theory assumes that individual particles move according to an external uniform strain field. Starting from this assumption, the macroscopic stiffness tensor can be derived (e.g. Liao \& Chang, 1997; Kruyt \& Rothenburg, 1998; Chang and Hicher, 2005; Luding, 2004; Luding, 2005):

$C_{\alpha \beta \gamma \phi}=\frac{1}{V} \sum_{p \in V}\left(k_{n} \sum_{c=1}^{N}\left(l^{2} / 2\right) n_{\alpha}^{c} n_{\beta}^{c} n_{\gamma}^{c} n_{\phi}^{c}+k_{t} \sum_{c=1}^{N}\left(l^{2} / 2\right) n_{\alpha}^{c} t_{\beta}^{c} n_{\gamma}^{c} t_{\phi}^{c}\right)$

where $\alpha, \beta, \gamma, \phi$ are subscripts that indicate the combinations of the vertical and horizontal directions, and $n$ and $t$ are the components of the normal and tangential unit vector at contact respectively, and $k_{n}$ and $k_{t}$ are non-linear stiffness given by Equations 16 and 17 . The shear 
modulus is associated with the term $C_{1212}$ of the stiffness tensor, where 1 and 2 are the vertical and horizontal direction respectively. Different expressions of $C_{1212}$ can be derived depending on the particle configuration.

\section{Micro-mechanical model: regular packings}

A simplified approach for deriving $C_{1212}$ and $\sigma_{i}^{*}$ was followed in this study, i.e. the soil aggregate was idealised as a packing of identical spherical particles in a regular structure. The lattice-type geometry of the system allows to derive explicit expressions of the macroscopic tensors. As an exercise, two different configurations (simple cubic, SC, and body centred cubic, BCC) were selected in order to ascertain the validity of the model irrespective of the choice of the particle configuration.

For the case of SC configuration (Figure 12a), the elementary averaging volume $V$ is a cube whose inscribed sphere is a single particle (or equally, a cube containing eight $1 / 8$ of a particle, whose corners are the centres of the particles):

SC: $V=(2 r)^{3}=8 r^{3}$

Thus, both $\sigma_{i}^{*}$ and $C_{1212}$ can be calculated from Equation 12 and 18 respectively as an average over 6 contacts, and are representative of the overall volume:

SC: $\quad \sigma_{i}^{*}=\frac{1}{V} \sum_{c=1}^{6} l^{c} f^{c}=\frac{2 l}{V} f$

SC: $C_{1212}=\frac{1}{V} \frac{l^{2}}{2}\left(k_{n} \sum_{c=1}^{6} n_{1}^{c} n_{2}^{c} n_{1}^{c} n_{2}^{c}+k_{t} \sum_{c=1}^{6} n_{1}^{c} t_{2}^{c} n_{1}^{c} t_{2}^{c}\right)=\frac{l^{2}}{V} k_{t}=\frac{2}{7} \frac{l^{2}}{V} k_{n}$

For the case of BCC configuration (Figure 12b), the elementary averaging volume is a cube containing a total of 2 particles (one whole particle placed in the centre of the cube, plus eight 
$1 / 8$ of a particle placed in each corner of the cube), whose corners are the centres of the eight particles surrounding the particle in the cube's centre:

BCC: $V=\left(\frac{4}{\sqrt{3}} r\right)^{3}=\frac{64}{3 \sqrt{3}} r^{3}$

Thus, both $\sigma_{i}^{*}$ and $C_{1212}$ can be calculated from Equation 12 and 18 respectively as an average over 8 contacts for each of the 2 particles within the averaging volume, and are representative of the overall volume:

BCC: $\sigma_{i}^{*}=\frac{1}{V} 2 \sum_{c=1}^{8} l^{c} f^{c}=\frac{16 l}{V} f$

BCC: $C_{1212}=\frac{1}{V} \frac{l^{2}}{2}\left[2\left(k_{n} \sum_{c=1}^{8} n_{1}^{c} n_{2}^{c} n_{1}^{c} n_{2}^{c}+k_{t} \sum_{c=1}^{8} n_{1}^{c} t_{2}^{c} n_{1}^{c} t_{2}^{c}\right)\right]=\frac{l^{2}}{V}\left(\frac{8}{9} k_{n}+\frac{16}{9} k_{t}\right)=\frac{88}{63} \frac{l^{2}}{V} k_{n}$

From Equation 20 and 23, we have:

SC: $f=\frac{\sigma_{i}^{*}}{2 l} V$

BCC: $f=\frac{\sigma_{i}^{*}}{16 l} V$

By combining Equations 21 and 24 with Equation 16 and Equations 25 and 26, two possible functional forms (one for each configuration) that link the shear modulus $C_{1212}$ with intergranular stress $\sigma_{i}^{*}$ can be derived. These functional forms were assumed to also characterise the relationship between the small-strain shear modulus $G_{0}$ of the unsaturated soil specimen and the suction/degree of saturation-induced intergranular stress, $\sigma_{i}$. In other words, $C_{1212}$ was replaced by $G_{o}$ and $\sigma_{i}^{*}$ was replaced by $\sigma_{i}$ (the latter given by Equation 9), leading to the following expressions:

$S C: G_{o} \equiv C_{1212}=\frac{2}{7} \frac{l^{2}}{V} \frac{3}{2} k_{n 0}{ }^{2 / 3}\left(\frac{\sigma_{i}^{*}}{2 l} V\right)^{1 / 3} \equiv \frac{2}{7} \frac{l^{2}}{V} \frac{3}{2} k_{n 0}{ }^{2 / 3}\left(\frac{\sigma_{i}}{2 l} V\right)^{1 / 3}$ 
BCC: $G_{o} \equiv C_{1212}=\frac{88}{63} \frac{l^{2}}{V} \frac{3}{2} k_{n 0}^{2 / 3}\left(\frac{\sigma_{i}^{*}}{16 l} V\right)^{1 / 3} \equiv \frac{88}{63} \frac{l^{2}}{V} \frac{3}{2} k_{n 0}^{2 / 3}\left(\frac{\sigma_{i}}{16 l} V\right)^{1 / 3}$

\section{CALIBRATION AND VALIDATION OF THE MODEL}

\subsection{Calibration against experimental data}

The proposed model was calibrated and validated against the experimental results obtained in this study. Two model parameters need to be identified, namely $k_{n 0}$ and $\sigma_{i}^{m}$. In the macroscopic model, these parameters should be intended as macroscopic parameters with an intuitive physical micro-scale meaning. In particular, $k_{n 0}$ does not represent anymore a material property as in the micro-mechanical model, but a model parameter that accounts for a number of characteristics of the real soil packing including the particle stiffness, particle shape, particle size distribution, particle arrangements etc.

A calibration procedure was devised to determine $k_{n 0}$ and $\sigma_{i}^{m}$ against the small-strain shear modulus at saturation, $G_{0}^{\text {sat }}$, and at residual saturation, $G_{0}^{\text {res }}$, respectively. An equivalent particle radius $r=l / 2=D_{50} / 2$ was also selected (although it can be shown that the choice of the equivalent particle radius does not affect the performance of the model, as it would just lead to different values of $k_{n 0}$ and $\sigma_{i}^{m}$ ).

\section{Calibration of $k_{n 0}$ at saturation}

The measurement of $G_{0}^{\text {sat }}$ was taken at the beginning of the drying path, after the saturation procedure. In this case, the intergranular stress in Equation 9 equals the confining pressure (cell pressure, $\left.\sigma_{C P}\right)$ only:

$\sigma_{i}=\left(\sigma_{i}\right)^{s a t}=\sigma-u_{w}=\sigma_{C P}$ 
The model parameter $k_{n 0}$ can therefore be derived by inverting Equations 27 and 28 with $G_{0}=G_{0}^{s a t}, \sigma_{i}=\sigma_{C P}$, and $l=2 r$

$\boldsymbol{S C}: \quad k_{n 0}=\left[\frac{14}{3} \frac{r G_{0}^{s a t}}{\left(2 r^{2} \sigma_{C P}\right)^{1 / 3}}\right]^{3 / 2}$

BCC: $k_{n 0}=\left[\frac{28}{11 \sqrt{3}} \frac{r G_{0}^{\text {sat }}}{\left(\frac{2}{3 \sqrt{3}} r^{2} \sigma_{C P}\right)^{1 / 3}}\right]^{3 / 2}$

Table 4 shows the calibrated parameter $k_{n 0}$ for $\mathrm{SC}$ and $\mathrm{BCC}$ configurations.

\section{Calibration of $\sigma_{i}^{\mathrm{m}}$ at residual saturation}

The measurement of the second parameter needed for calibration, $G_{0}^{r e s}$, was taken at the end of the main drying path, where $S_{r}=S_{r m}$. In this situation, the intergranular stress $\sigma_{i}$ in Equation 9 depends on the confining pressure $\sigma_{C P}$ and on the (unknown) intergranular stress at meniscus contacts $\sigma_{i}^{m}$, regardless of suction:

$\sigma_{i}=\left(\sigma_{i}\right)^{r e s}=\sigma_{i}^{m}+\sigma_{C P}$

The model parameter $\sigma_{i}^{m}$ can therefore be derived by inverting Equations 27 and 28 with $G_{0}=G_{0}^{r e s}, \sigma_{i}=\sigma_{i}^{m}+\sigma_{C P}$, and $l=2 r:$

SC: $\sigma_{i}^{m}=\frac{1}{2 r^{2}}\left(\frac{14}{3} \frac{r G_{0}^{r e s}}{k_{n 0}^{2 / 3}}\right)^{3}-\sigma_{C P}$

BCC: $\sigma_{i}^{m}=\frac{3 \sqrt{3}}{2 r^{2}}\left(\frac{28}{11 \sqrt{3}} \frac{r G_{0}^{r e s}}{k_{n 0}^{2 / 3}}\right)^{3}-\sigma_{C P}$

Table 4 shows the parameter $\sigma_{i}^{m}$ for both $\mathrm{SC}$ and $\mathrm{BCC}$ configurations. As a result of the calibration procedure against the experimental data, the values of $\sigma_{i}^{m}$ are identical. 


\subsection{Validation against experimental data}

The proposed model for the small-strain shear modulus $G_{0}$ of unsaturated soils was validated against the results of the experimental investigation carried out in this study. It is worth noticing that the macro-scale model was built upon a simple micro-mechanical model consisting of ordered packings of mono-sized spheres. It was implicitly assumed that the macro-scale model derived therefrom could be extended to non-ordered packing of non-round and rough spheres. In particular, it was assumed that the stress tensor generated by the meniscus water and bulk water is isotropic.

Once the parameter $\sigma_{i}^{m}$ was derived at residual saturation, the intergranular stress $\sigma_{i}$ and corresponding intergranular force were calculated along the drying and wetting paths (Equation 9 and 25 for SC and Equation 9 and 26 for BCC, with $\sigma_{i}=\sigma_{i}^{*}$ ). From the value of $k_{n 0}$ previously calibrated, the stiffness values $k_{n}$ and $k_{t}$ were calculated for each combination of suction and degree of saturation (Equation 16 and 17), and were used to derive $C_{1212}$ (Equation 21 and 24). As a consequence of the calibration procedure against experimental data, the values of $C_{1212}$ for the two configurations were found to be identical.

Figure $13 a$ shows the comparison between the values of $G_{0}$ obtained experimentally and the simulated stiffness $C_{1212}$. In order to take into account the variability of the degree of saturation within the specimen, bounding values of $C_{1212}$ were estimated. To this end, the specimen was considered homogenous and characterised by values of suction and degree of saturation corresponding either to the top or the bottom of the specimen, as schematically shown in Figure 13b-c. The model gives an accurate prediction of the small-strain shear modulus during hydraulic hysteresis. The variation of $G_{0}$ with suction is well captured at a qualitative and quantitative level. 


\section{DISCUSSION}

The proposed model was used to elucidate the mechanisms behind different patterns of smallstrain response in unsaturated granular materials. Two key responses were explored: soils have been observed to exhibit a stiffer behaviour along either a drying or a wetting path, and the mechanisms leading to either behaviour are still unclear; furthermore, $G_{0}$ has been observed to vary in either a monotonic or non-monotonic fashion. Again, the mechanisms behind either response have never been expounded.

\subsection{Influence of the breadth of the water retention curves on the variation of $G_{0}$}

Let us consider two ideal soils, soil $A$ and soil $B$. Let us assume that the soils show the same small-strain shear modulus at saturation $\left(G_{0}^{\text {sat }}\right)$ and residual state $\left(G_{0}^{\text {res }}\right)$. Therefore, the parameters of the proposed model, $k_{n 0}$ and $\sigma_{i}^{m}$, will be the same for the two soils.

Let us now assume that the breadths of the main water retention curves are different for the two soils. The water retention behaviour of soil $A$ develops over a narrower range of suction than soil $B$, as shown in Figure 14a. Let us also assume that the two soils reach the same residual degree of saturation, $S_{r}^{m}$.

The small-strain stiffness returned by the model is shown in Figure 14b. Soil A appears to be stiffer upon a wetting path and shows a monotonic variation of $G_{0}$ with suction. On the other hand, soil $B$ is stiffer upon a drying path and exhibits a non-monotonic variation of $G_{0}$ with suction.

The reason for this behaviour lies on the evolution of the suction/degree of saturation-induced intergranular stress of the two soils. Figure $14 c$ shows the intergranular stress in the bulk water region $\left(\sigma_{i}^{b}\right.$, saturated contact) and in the meniscus water region $\left(\sigma_{i}^{m}\right.$, meniscus contact) versus suction. For soil $A$, the stress $\sigma_{i}^{b}$ never exceeds $\sigma_{i}^{m}$, i.e. the whole water retention behaviour is 
contained in a range of suction where the contribution of the menisci to the intergranular stress of the packing $\sigma_{i}$ is always higher than the contribution of suction at the saturated contact. Since the effect of the menisci is more significant along the wetting path (i.e. where the degree of saturation is smaller), the soil exhibits a stiffer behaviour upon wetting.

For soil $B$, the stress $\sigma_{i}^{b}$ becomes higher than $\sigma_{i}^{m}$ as suction increases. As a result, the soil becomes stiffer upon a drying path because the degree of saturation is higher and the region occupied by the bulk water is larger than the region occupied by the menisci. In this case, the variation of $G_{0}$ with suction becomes non-monotonic. This is associated with the intergranular stress initially being dominated by the intergranular stress in the bulk water and then controlled only by intergranular stress associated with the menisci at high suction.

\subsection{Influence of meniscus intergranular stress on the variation of $G_{0}$}

Let us now consider the case of soils $C$ and $D$, having the same water retention characteristics (Figure 15a), the same small-strain shear modulus at saturation $\left(G_{0}^{\text {sat }}\right)$ but different values of small-strain shear modulus at residual saturation $\left(G_{0}^{\text {res }}\right)$. In this case, the parameter $k_{n 0}$ will be the same for the two soils, whereas $\sigma_{i}^{m}$ will assume two different values.

Figure $15 b$ shows the evolution of the simulated shear modulus. Soil $C\left(\sigma_{i}^{m}=30 \mathrm{kPa}\right)$ exhibits a stiffer behaviour upon wetting, with a monotonic variation of $G_{0}$ with suction. Soil $D$ $\left(\sigma_{i}^{m}=5 \mathrm{kPa}\right)$ is instead stiffer upon drying, with a non-monotonic variation of $G_{0}$.

For soil $C$, the intergranular stress $\sigma_{i}^{b}$ remains smaller than $\sigma_{i}^{m}$ for the whole range of suction (Figure $15 c$ ), causing the soil to be stiffer upon a wetting path and $G_{0}$ to vary in a monotonic fashion. For soil $D$, the intergranular stress $\sigma_{i}^{b}$ becomes higher than $\sigma_{i}^{m}$ within the explored suction range, causing the soil to become stiffer upon a drying path and $G_{0}$ to vary in a nonmonotonic fashion. 
'A microscale-based model for small-strain stiffness in unsaturated granular geomaterials' Submitted to Géotechnique 


\section{CONCLUSIONS}

The paper has presented a simple macroscopic model for the small-strain shear modulus of unsaturated granular soils based on a micro-mechanical approach. The model accounts for the independent effect of suction and degree of saturation on soil stiffness. It is based upon the knowledge of the soil water retention curves, and on two parameters that can be easily calibrated against the small-strain stiffness measured at saturation and at residual state. The performance of the model was assessed against experimental data on an unsaturated sand specimen. The soil behaviour observed experimentally was successfully reproduced both at a qualitative and quantitative level. The model captures the higher stiffness observed along a wetting path that the stress variable obtained as the product 'suction times degree of saturation' fails to predict.

According to the proposed model, the evolution of $G_{0}$ is controlled by the evolution of the suction/degree of saturation-induced intergranular stress during hydraulic hysteresis. It has been shown that the breadth of the water retention curve and the intensity of the intergranular stress due to the presence of the menisci have an effect on the evolution of $G_{0}$. When the intergranular stress at meniscus contacts is higher than the intergranular stress at saturated contacts and/or the water retention curves develop over a relatively narrow suction range, soil is stiffer during wetting, and the variation of $G_{0}$ is monotonic. When the intergranular stress at meniscus contacts becomes smaller than the one at saturated contacts and/or the water retention curves develop over a relatively large suction range, the soil becomes stiffer during drying, and the variation of $G_{0}$ is nonmonotonic.

\section{ACKNOWLEDGEMENTS}


The authors would like to thank Derek McNee for his contribution to the construction of the sand pluviator and the height-adjustable water reservoir system used during the experimental investigation carried out in this study.

\section{REFERENCES}

Bishop, A. W., 1959. The principle of effective stress. Tek. Ukeblad, Volume 39, p. 859-863.

Blewett, J., Blewett, I. J. \& Woodward, P. K., 2000. Phase and amplitude responses associated with the measurement of shear-wave velocity in sand by bender elements. Canadian Geotechnical Journal, Volume 37, pp. 1348-1357.

Boso, M., Tarantino, A. \& Mongiovì, L., 2005. Shear strength behaviour of a reconstituted clayey silt. Unsaturated soils - Mancuso \& Tarantino (eds) - 2005 Taylor \& Francis Group, London, pp. 9-14.

Chang, C. S. \& Hicher, P. -Y., 2005. An elasto-plastic model for granular materials with microstructural consideration. Int. Journal of Solids and Structures, Volume 42, pp. 4258-4277.

Digby, P. J., 1981. The effective moduli of porous granular rock. J. Appl. Mech., Volume 48, p. 803-808.

Dong, Y. \& Lu, N., 2016. Correlation between small-strain shear modulus and suction stress in capillary regime under zero total stress conditions. Journal of Geotechnical and Geoenvironmental Engineering, 10.1061/(ASCE)GT.1943-5606.

Dyvik, R. \& Madshus, C., 1985. Lab measurements of Gmax using bender element. Proc., ASCE Convention on Advances in the Art of Testing Soils under Cyclic Conditions, p. 186-196.

Fernandez, A. L., 2000. Tomographic imaging the state of stress. PhD thesis Civil Engineering, Georgia Institute of Technology, Atlanta.

Fisher, R. A., 1926. On the capillary forces in an ideal soil; correction on formulae given by W. B. Haines. Journal of Agricultural Science, Volume 16, pp. 492-505. 
Hardin, B. O., 1978. The Nature of Stress Stain Behavior of Soils. Earthquake Engineering and Soil Dynamics, ASCE, pp. 3-90.

Hardin, B. O. \& Black, W. L., 1968. Vibration modulus of normally consolidated clay. Journal of the Soil Mechanics and Foundations Division, ASCE, 94(SM2), pp. 353-369.

Hardin, B. O. \& Drnevich, V. P., 1972. Shear modulus and damping in soils: design equations and curves. Journal of the Soil Mechanics and Foundations Division, ASCE, 98(SM7), pp. 667-692.

Hardin, B. O. \& Richart, F. E., 1963. Elastic wave velocities in granular soils. Journal of Soil Mechanics and Foundations Division, ASCE, 89(SM1), pp. 33-65.

Iwasaki, T., Tatsuoka, F., Tokida, K. \& Yasuda, S., 1978. A practical method for assessing soil liquefaction potential based on case studies at various sites in Japan. Proc., 2nd Int. Conf. on Microzonation, San Francisco, p. 885-896.

Jommi, C., 2000. Remarks on the constitutive modelling of unsaturated soils. Experimental evidence and theoretical approaches in unsaturated soils (eds A. Tarantino and C. Mancuso). Rotterdam: Balkema, pp. 139-153.

Jovicic, V. \& Coop, M. R., 1997. Interpretation of bender element tests. Géotechnique, 47(3), p. 875.

Khosravi, A. \& McCartney, J. S., 2011. Resonant column test for unsaturated soils with suction-saturation control. Geotechnical Testing Journal, 36(6), pp. 1-10.

Khosravi, A. \& McCartney, J. S., 2012. Impact of hydraulic hysteresis on the small-strain shear modulus of low plasticity soils. Journal of Geotechnical and Geoenvironmental Engineering, 10.1061/(ASCE)GT.19435606, p. 1326-1333.

Khosravi, A. et al., 2016. Characterizing the variation of small strain shear modulus for silt and sand during hydraulic hysteresis. Proc. 3rd European Conference on Unsaturated Soils “E-UNSAT 2016” - E3S Web Conferences, Volume 9.

Kruyt, N. P. \& Rothenburg, L., 1998. Statistical theories for the elastic moduli of two-dimensional assemblies of granular materials. International Journal of Engineering Science, Volume 36, pp. 1127-1142. 
Kruyt, N. P. \& Rothenburg, L., 2001. Statistics of the elastic behaviour of granular materials. Int. Journal of Solids and Structures, Volume 38, pp. 4897-4899.

Lee, J. \& Santamarina, J. C., 2005. Bender Elements: performance and signal interpretation. Journal of Geotechnical and Geoenvironmental Engineering, 131(9), pp. 1063-1070.

Leong, E. C., Yeo, S. H. \& Rahardjo, H., 2005. Measuring shear wave velocity using bender elements. Geotechnical Testing Journal, 28(5), pp. 488-498.

Liao, C. -L. \& Chang, T. -C., 1997. A generalized constitutive relation for a randomly packed particle assembly. Computers and Geotechnics , 20(3/4), pp. 345-363.

Love, A. E. H. (1927). A Treatise on the Mathematical Theory of Elasticity, 4th Edition. Dover, New York.

Luding, S., 2004. Micro-macro models for anisotropic granular media. Modelling of cohesive-frcitional materials. Vermeer, Ehlers, Hermann \& Ramm, Taylor \& Francis Group, London, pp. 195-206.

Luding, S., 2005. Anisotropy in cohesive, frictional granular media. Journal of Physics Condensed Matter, 17(24), p. S2623-S2640.

Mancuso, C., Vassallo, R. \& d'Onofrio, A., 2002. Small strain behaviour of a silty sand in controlled-suction resonant column-torsional shear tests. Canadian Geotechnical Journal, 39(1), pp. 22-31.

Marinho, F. A. M., Chandler, R. J. \& Crilly, M. S., 1995. Stiffness measurements on an unsaturated high plasticity clay using bender elements. Unsaturated soils. Proc. 1st International Conference on Unsaturated Soils, UNSAT 95, Paris, France, 6-8 September 1995. A.A. Balkema, Rotterdam, Volume 1, pp. 535-539. Mendoza, C. E., Colmenares, J. E. \& Merchàn, V. E., 2005. Stiffness of an unsaturated compacted clayey soil at very small strains. Proc., Int. Symp. on Advanced Experimental Unsaturated Soil Mechanics, ASCE, Reston, VA, pp. 199-204.

Ng, C. W. W. \& Xu, J., 2012. Effects of current suction ratio and recent suction history on small-strain behaviour of an unsaturated soil. Canadian Geotechnical Journal, Volume 49, pp. 226-243. 
Ng, C. W. W., Xu, J. \& Yung, S. Y., 2009. Effects of imbibition drainage and stress ratio on anisotropic stiffness of an unsaturated soil at very small strains. Canadian Geotechnical Journal, 46(9), pp. 1062-1076.

Oh, W. T. \& Vanapalli, S. K., 2014. Semi-empirical model for estimating the small-strain shear modulus of unsaturated non-plastic sandy soils. Geotechnical and Geological Engineering, 32(2), pp. 259-271.

Qian, X., Gray, D. H. \& Woods, R. D., 1993. Voids and granulometry: effects on shear modulus of unsaturated sands. Journal of Geotechnical Engineering, 119(2), pp. 295-314.

Rampello, S., Viggiani, G. \& Amorost, A., 1997. Small-strain stiffness of reconstitued clay compressed along constant triaxial effective stress ratio path. Géotechnique, 47(3), pp. 475-489.

Santamarina, J. C. \& Fam, M. A., 1997. Interpretation of bender element tests - discussion. Géotechnique, 47(4), p. 873-875.

Sawangsuriya, A., Edil, T. B. \& Bosscher, P. J., 2009. Modulus-suction moisture relationship for compacted soils in post compaction state. Journal of Geotechnical and Geoenvironmental Engineering, 10.1061/(ASCE)GT.1943-5606.0000108, p. 1390-1403.

Senthilmurugan, T. \& Ilamparuthi, K., 2005. Study of compaction characteristics and strength through ultrasonic methods. Proc. of Geo-Frontiers Conference, Austin, ASCE, Geotechnical Special Publication no. 130, pp. 1-12.

Shirley, D. J. \& Hampton, L. D., 1978. Shear wave measurements in laboratory sediments. Journal of Acoustic Society of America, 63(2), p. 607-613.

Sorensen, K. K., Baudet, B. A. \& Simpson, B., 2010. Influence of strain rate and acceleration on the behaviour of reconstituted clays at small strains. Géotechnique, 60(10), pp. 751-763.

Stanier, S. \& Tarantino, A., 2013. An approach for predicting the stability of vertical cuts in cohesionless soils above the water table. Engineering Geology, Volume 158, p. 98-108.

Stokoe, K. H. et al., 1995. Effects of various parameters on the stiffness and damping of soils at small to medium strains. Pre-failure Deformation of Geomaterials, Balkema, Rotterdam, Volume 2, pp. 785-816. 
van Genuchten, M., 1980. A closed-form equation for predicting the hydraulic conductivity of unsaturated soils. Soil Sci. Soc. Am. J. , Volume 44, p. 892-898.

Viana da Fonseca, A., Ferreira, C. \& Fahey, M., 2009. A framework for interpreting bender element tests, combining time-domain and frequency-domain methods. Geotechnical Testing Journal, 32(2), pp. 1-17.

Viggiani, G. \& Atkinson, J. H., 1995a. Interpretation of bender element tests. Géotechnique, 45(1), pp. 149154.

Viggiani, G. \& Atkinson, J. H., 1995b. Stiffness of fine grained soils at very small strains. Géotechnique, 45(2), pp. 249-265.

Waltonn, K., 1987. The effective elastic moduli of a random packing of spheres. Journal of the Mech. Phys. Solids, Volume 35, p. 213-226.

Weidinger, D. M., Ge, L. \& Stephenson, R. W., 2009. Ultrasonic pulse velocity tests on compacted soil. Characterization, Modeling, and Performance of Geomaterials, Hunan, ASCE, Geotechnical Special Publication, no. 189, pp. 150-155.

Wong, K. S., Mašín, D. \& Ng, C. W. W., 2014. Modelling of shear stiffness of unsaturated fine grained soils at very small strains. Computers and Geotechnics, Volume 56, pp. 28-39. 


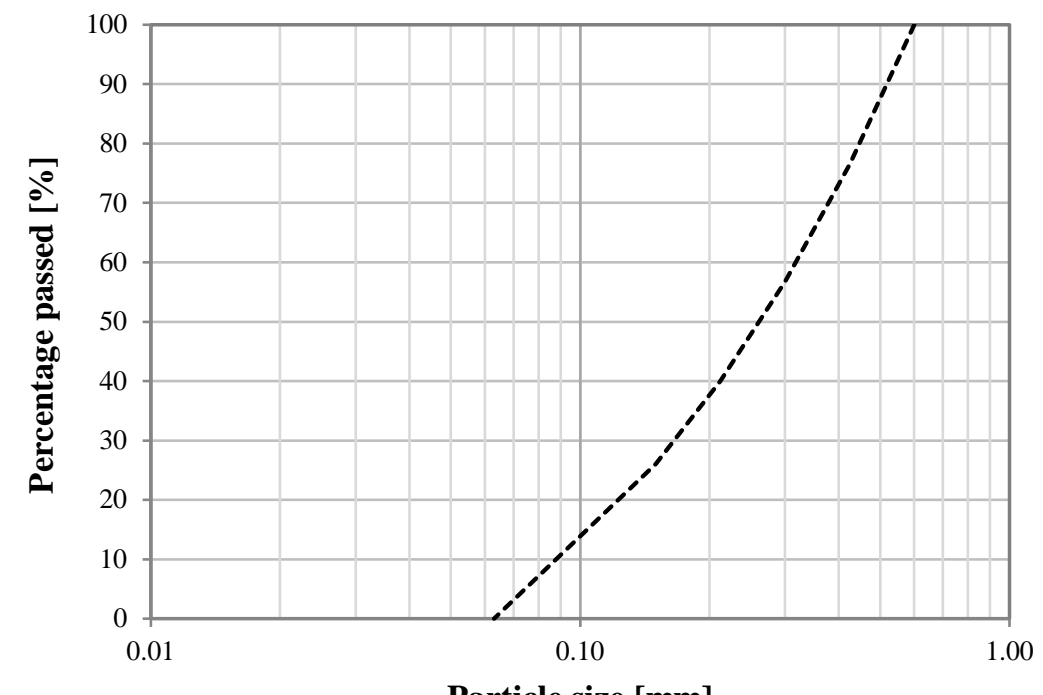

Particle size [mm]

Particle size [mm] 


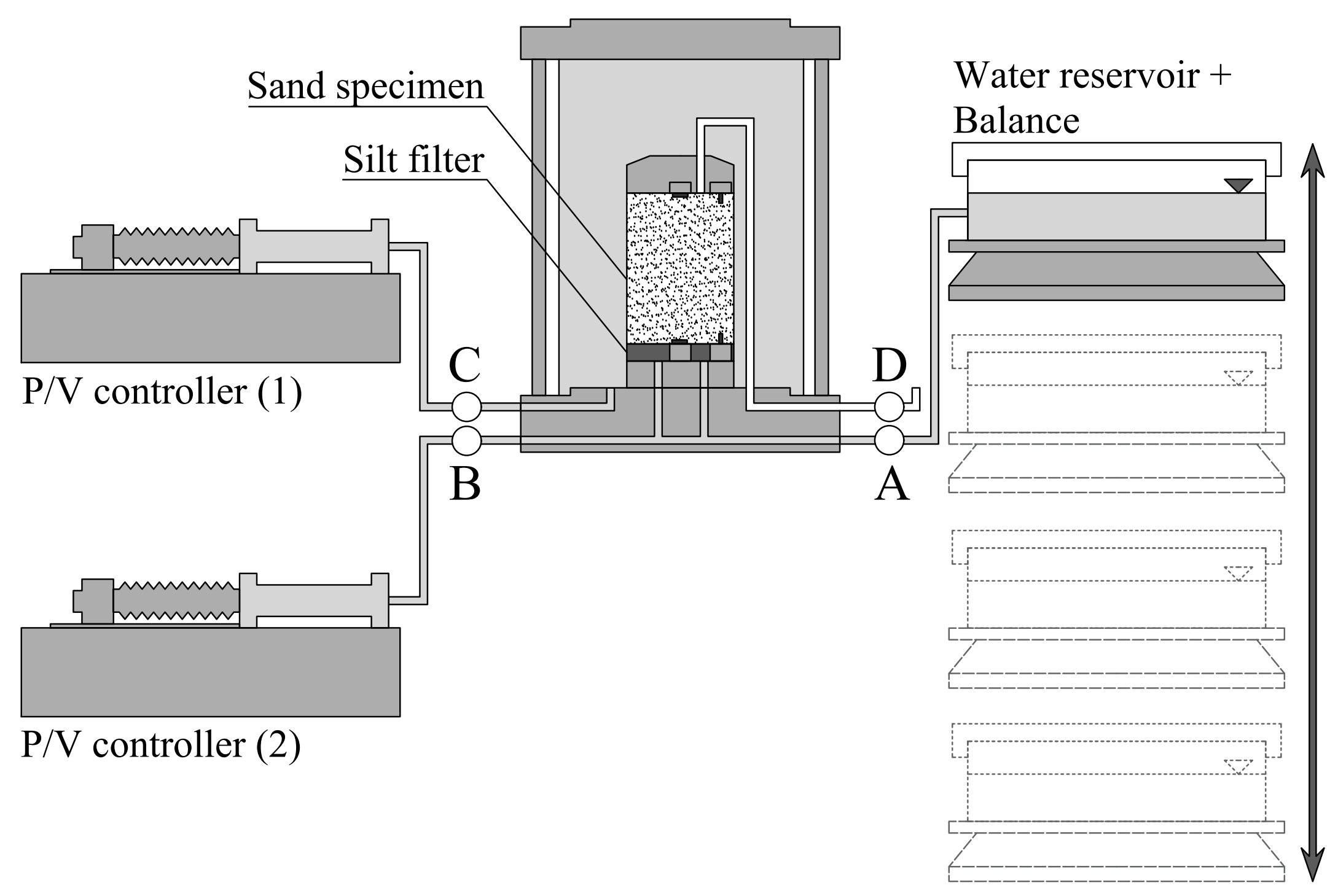




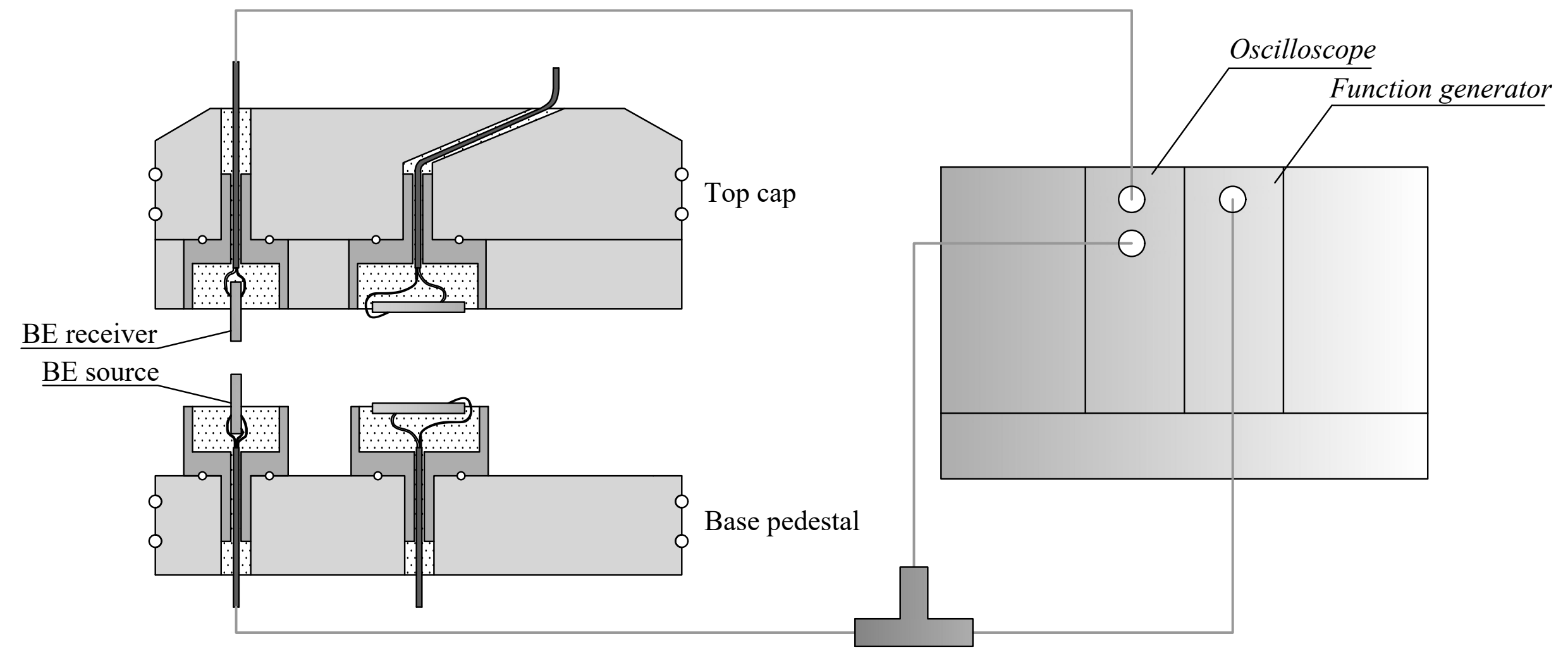




\section{Closed position}

\section{Open position}

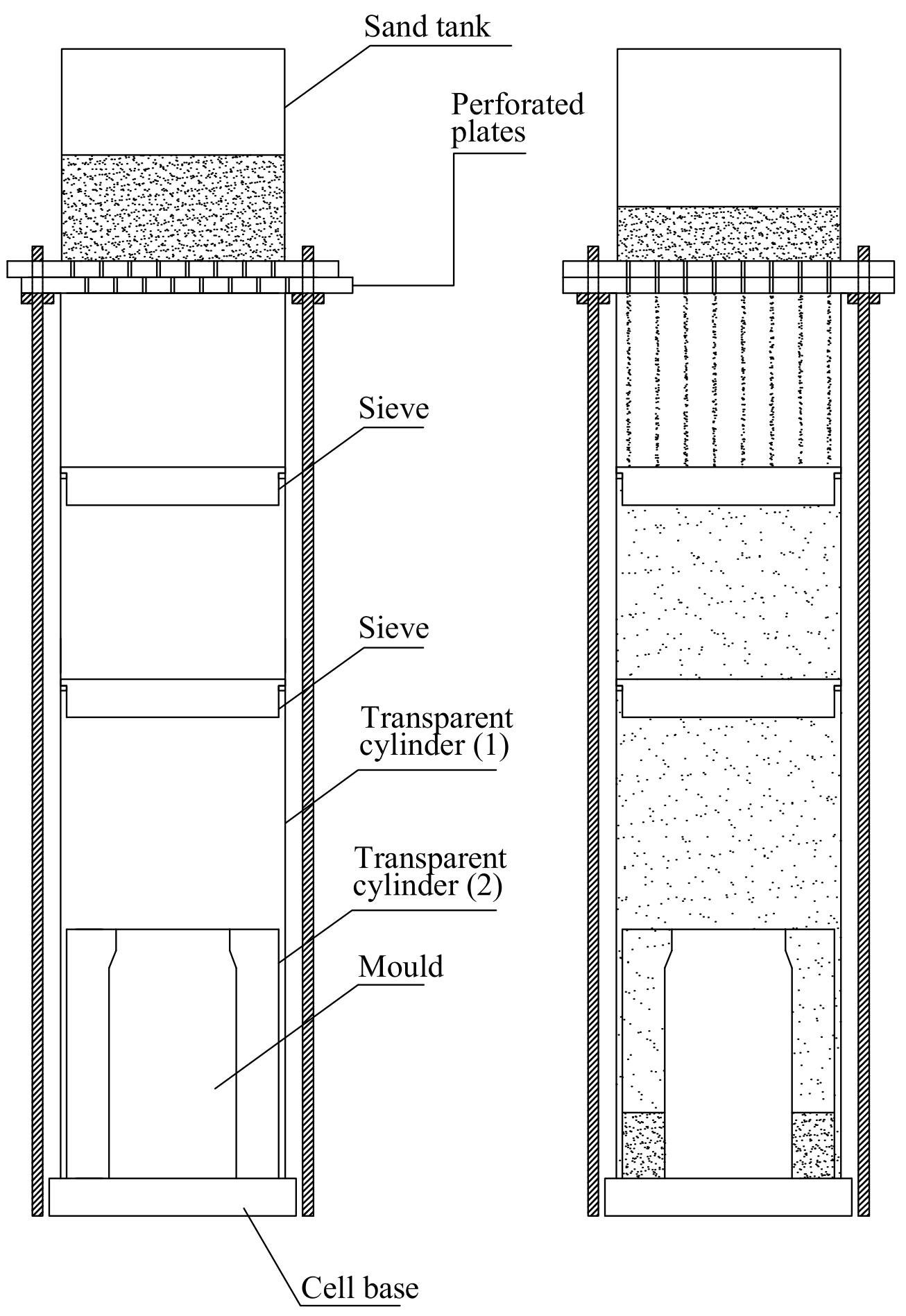




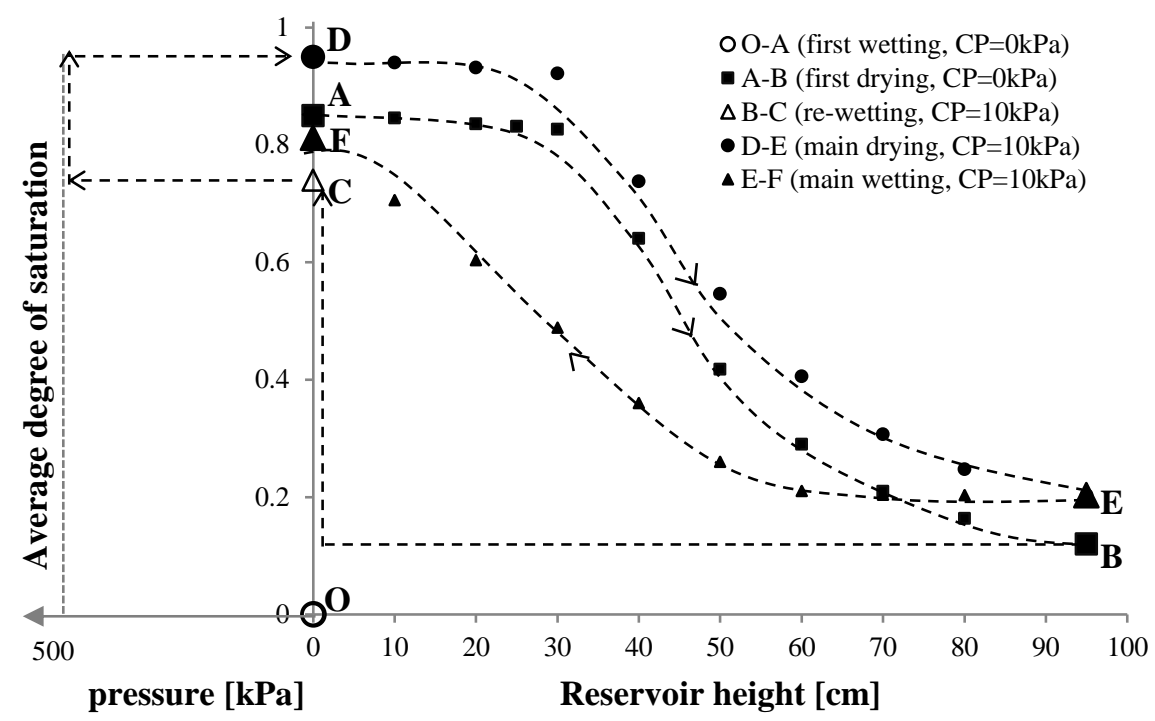




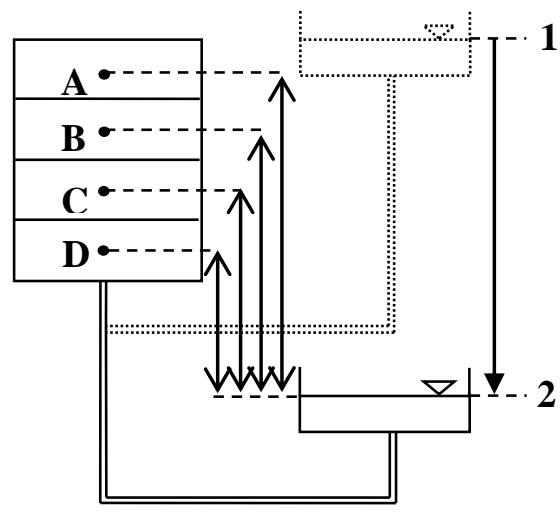

a)

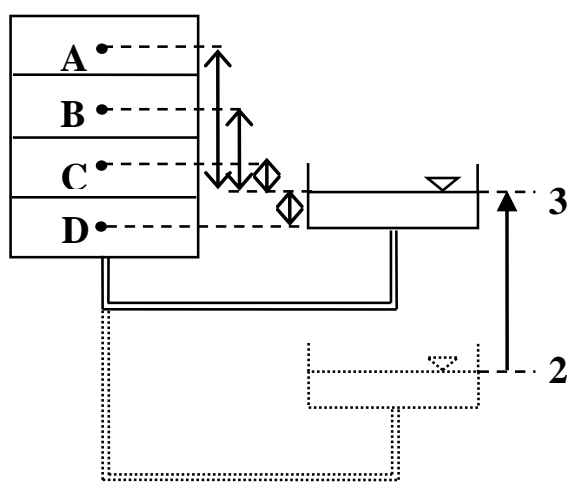

b)

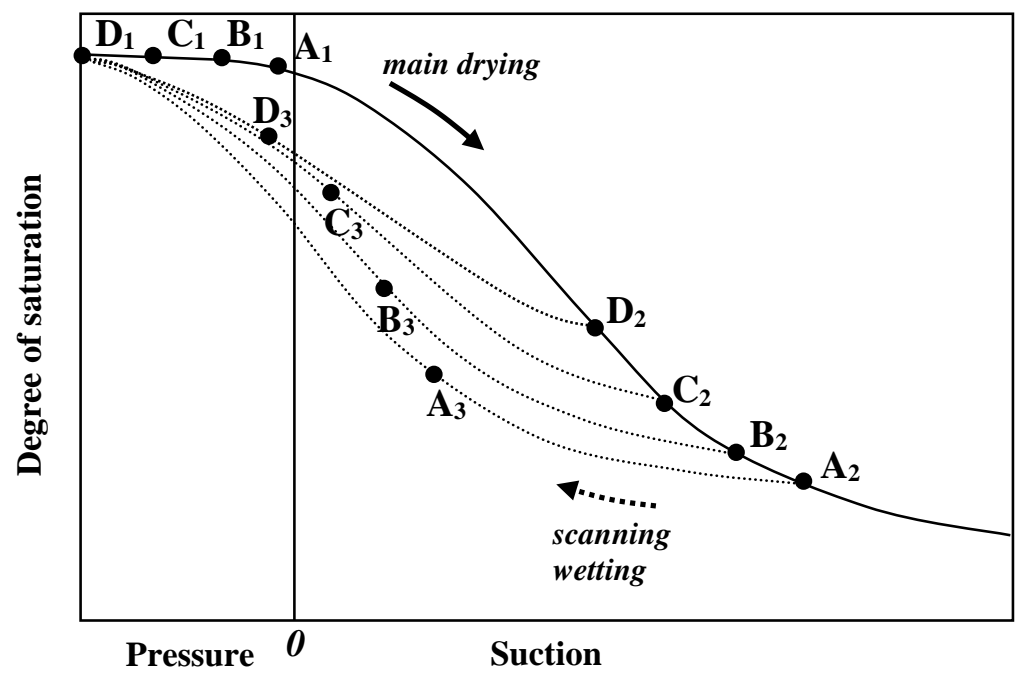




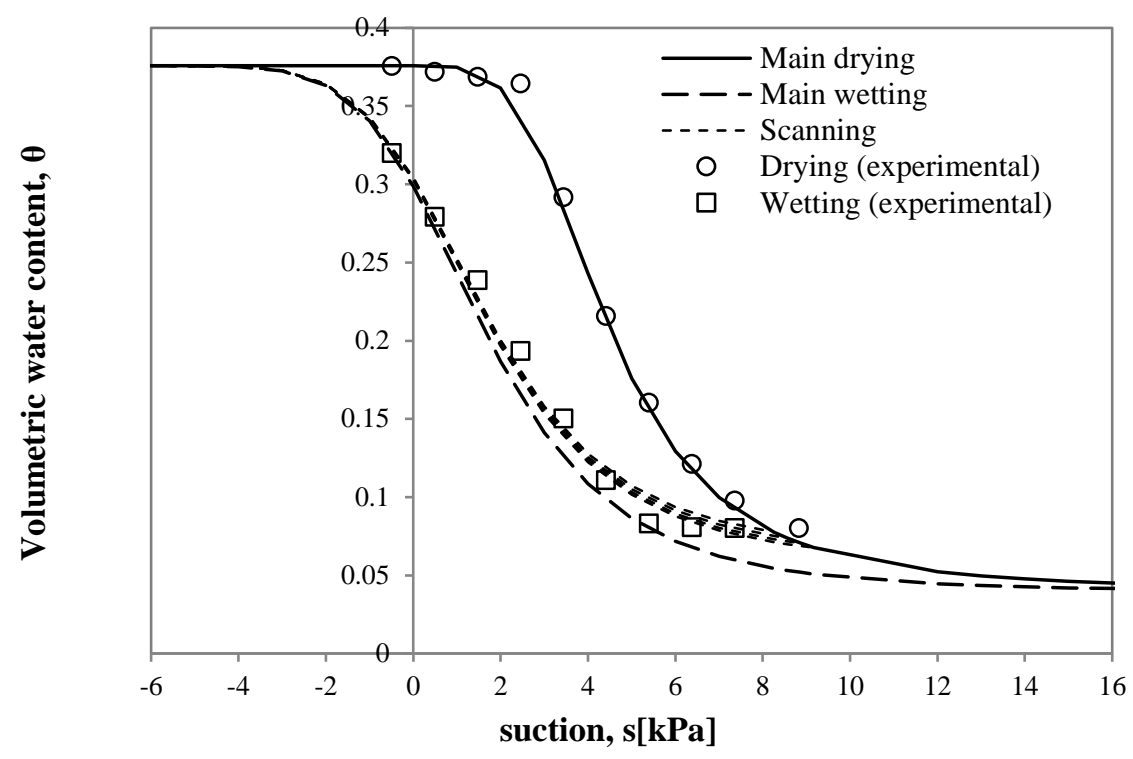




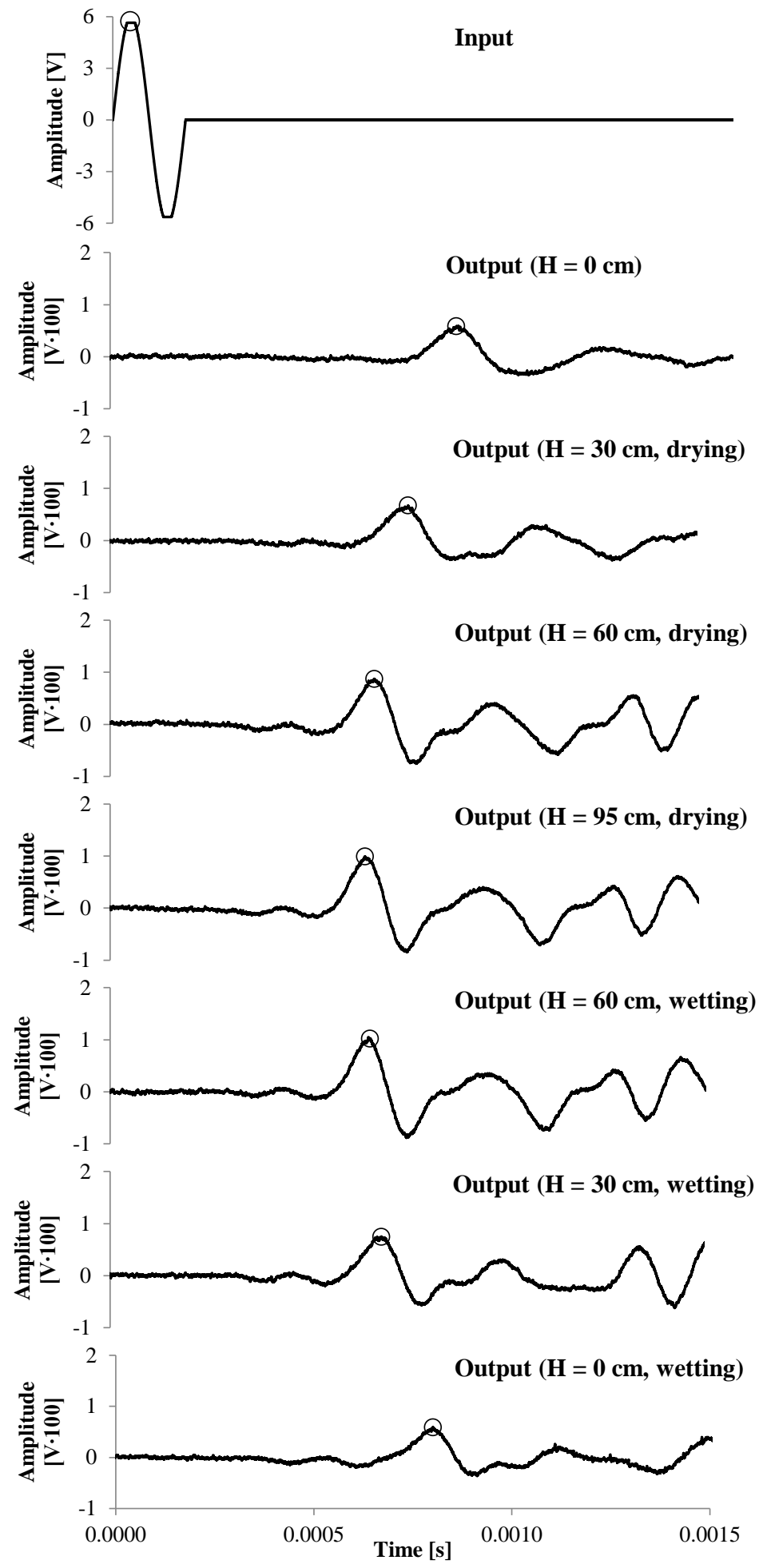


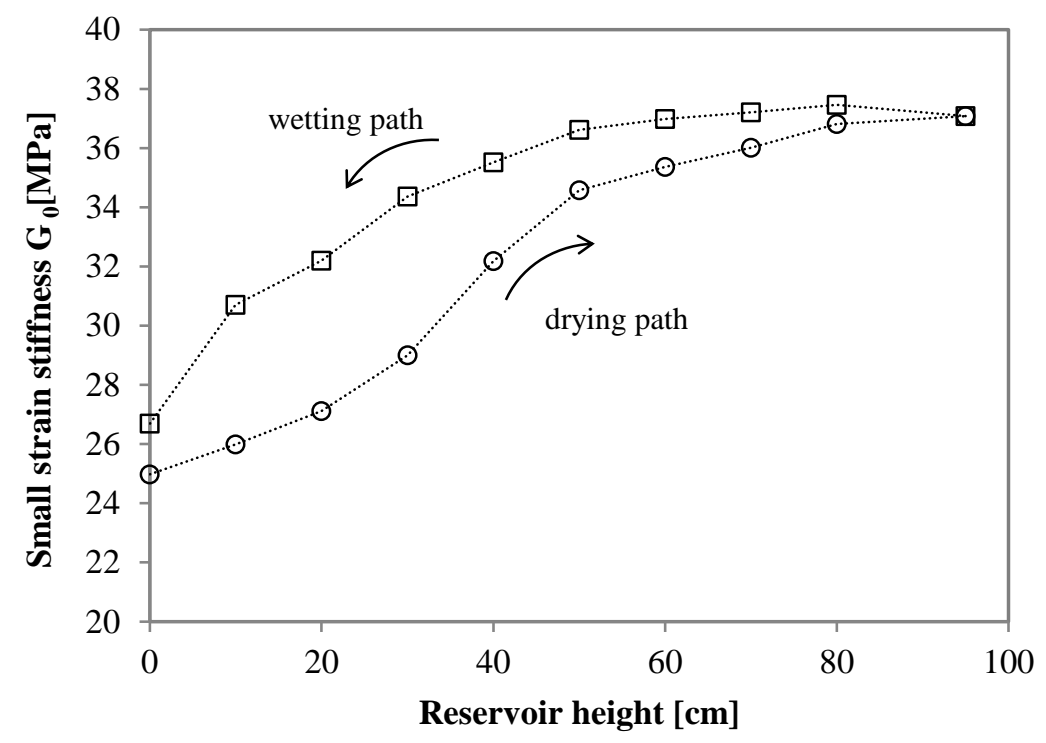




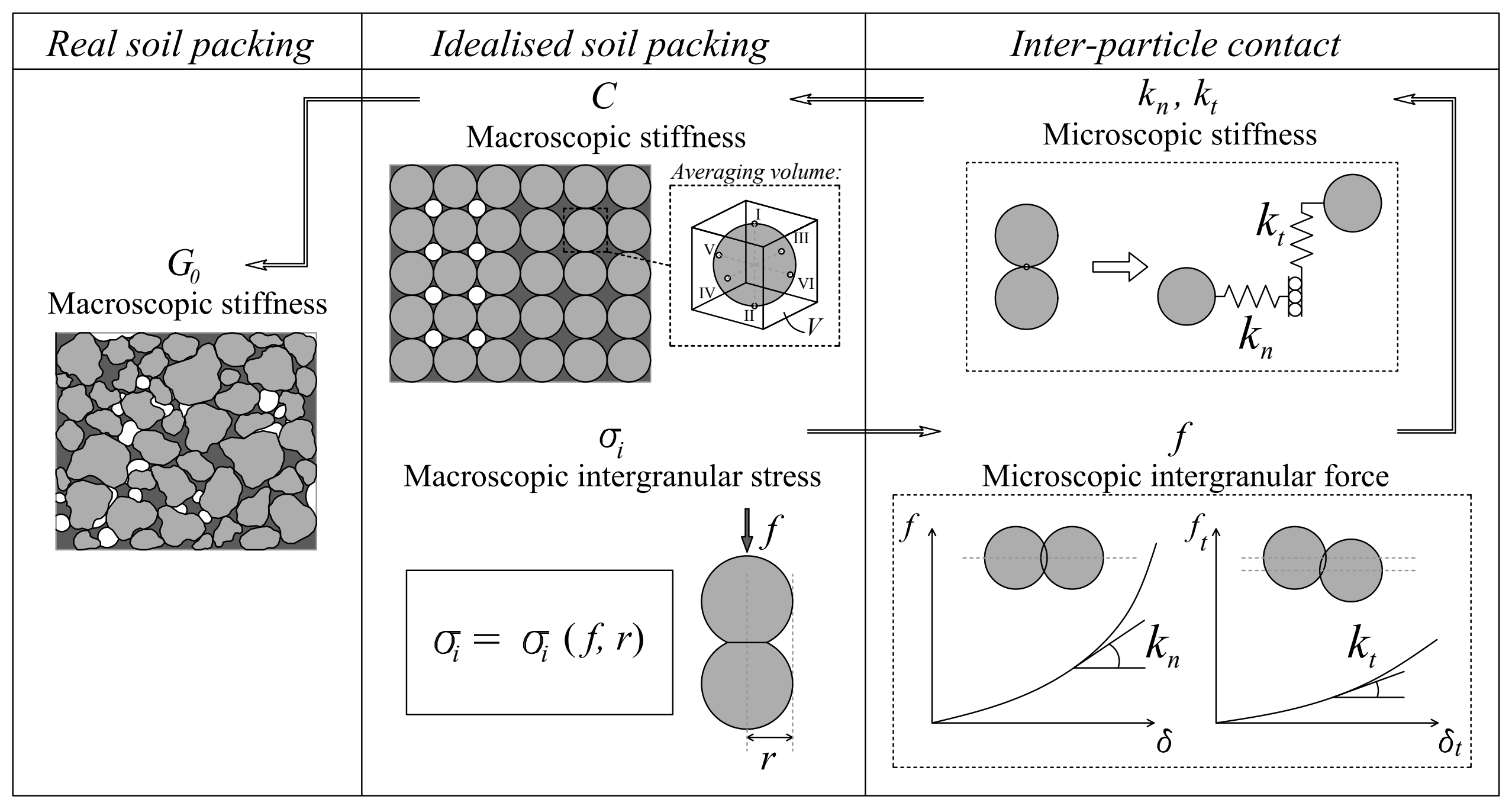




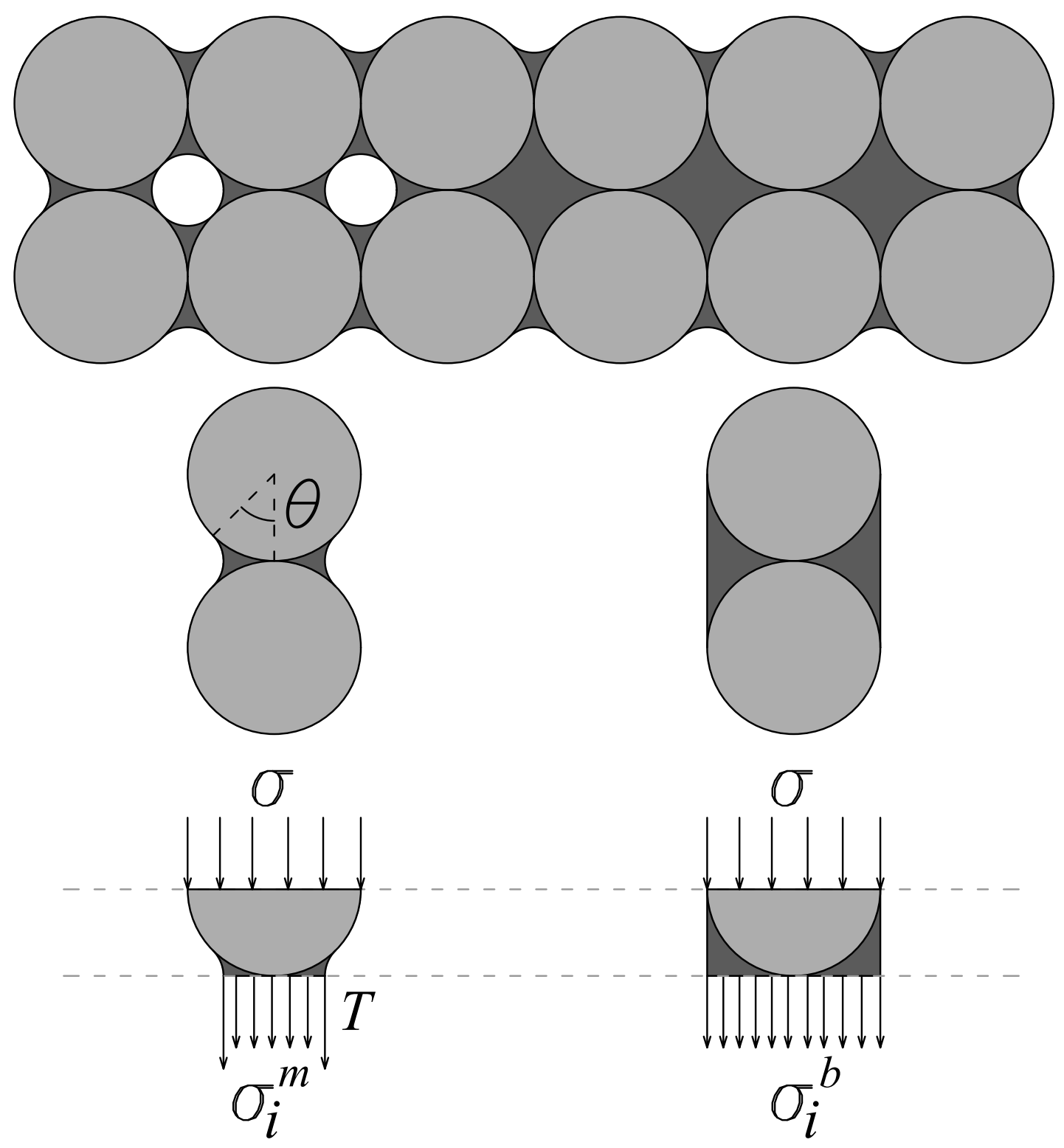




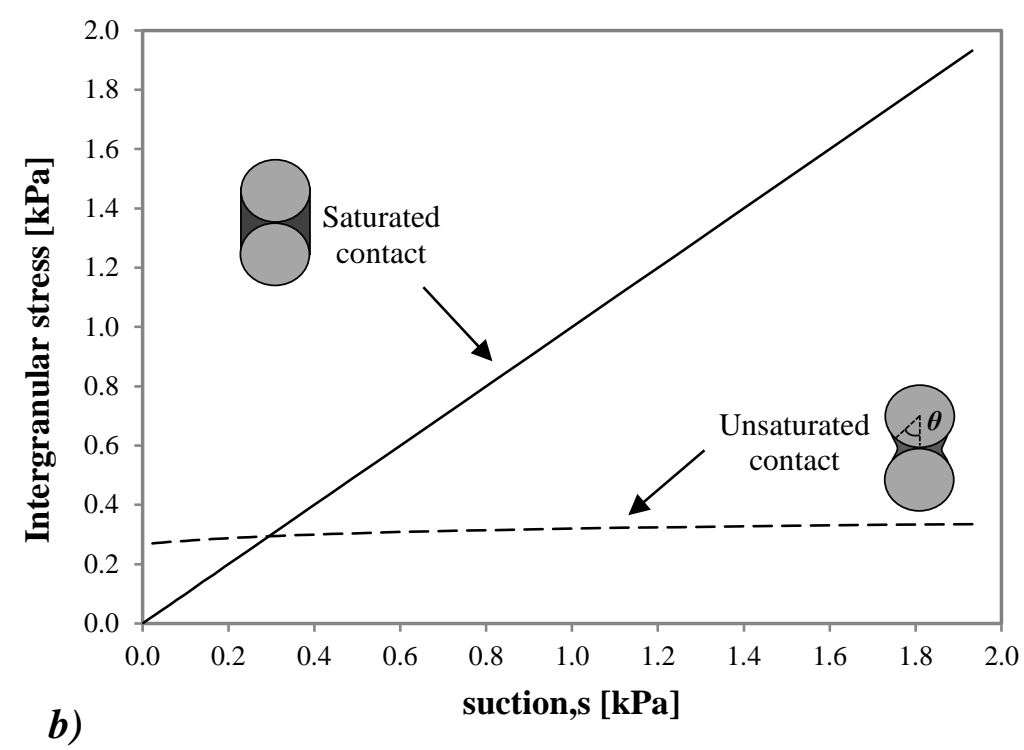

b) 


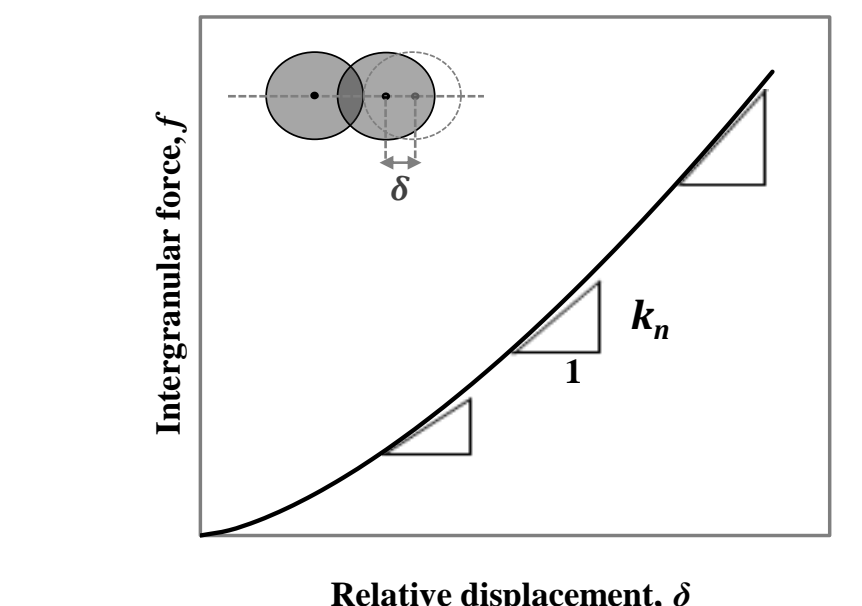

Relative displacement, $\delta$

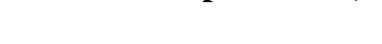

Click here to access/download;Figure;Figure11.xlsx $\Perp$ 

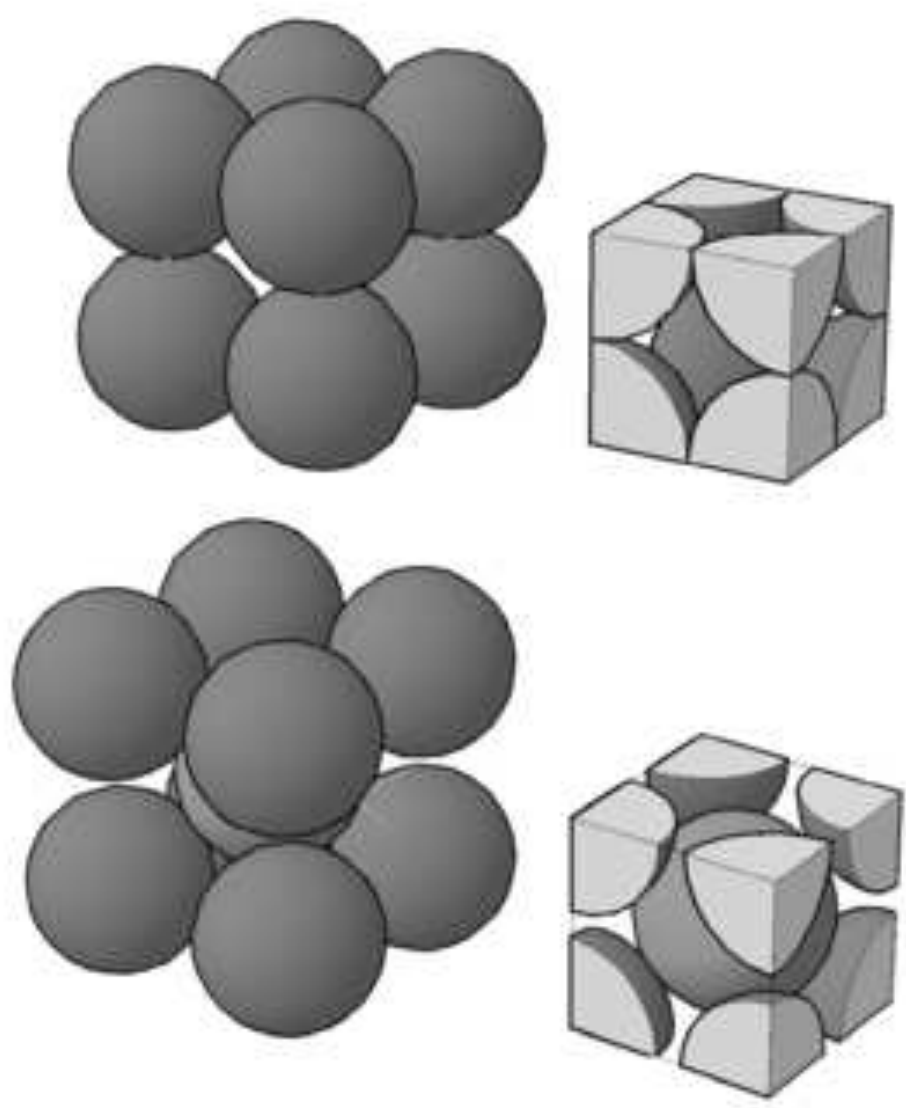


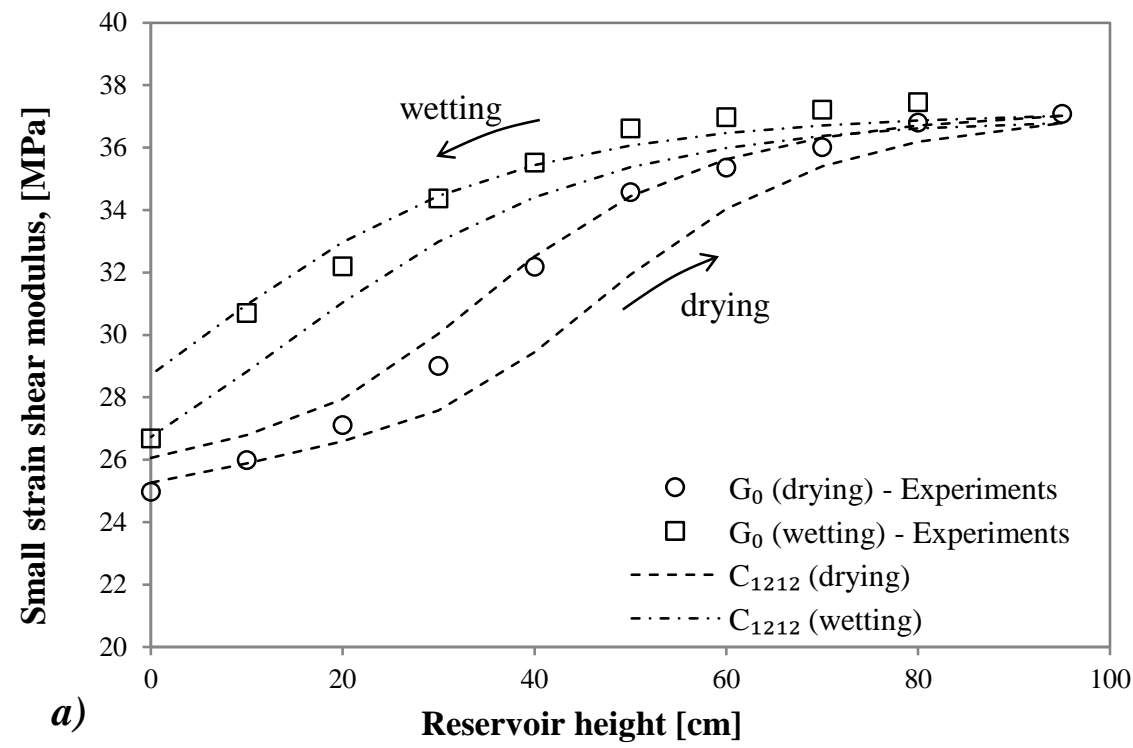




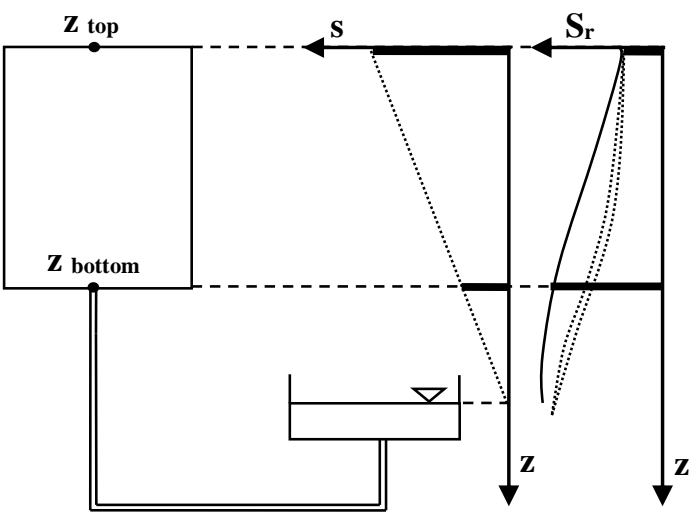

b) Main drying

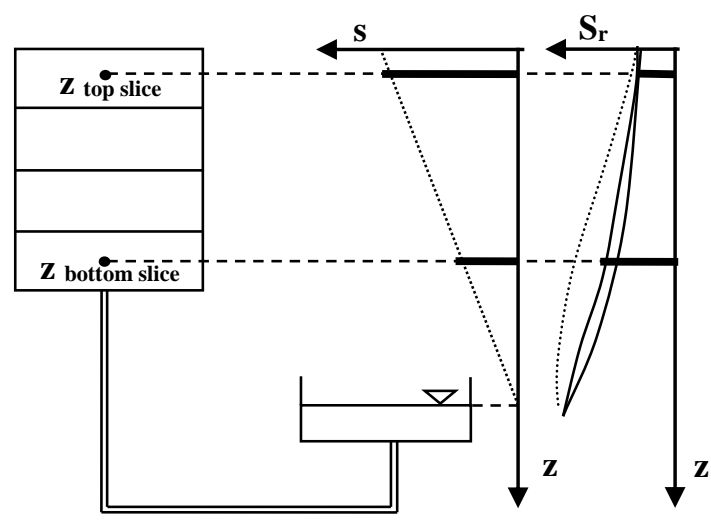

c) Scanning wetting 

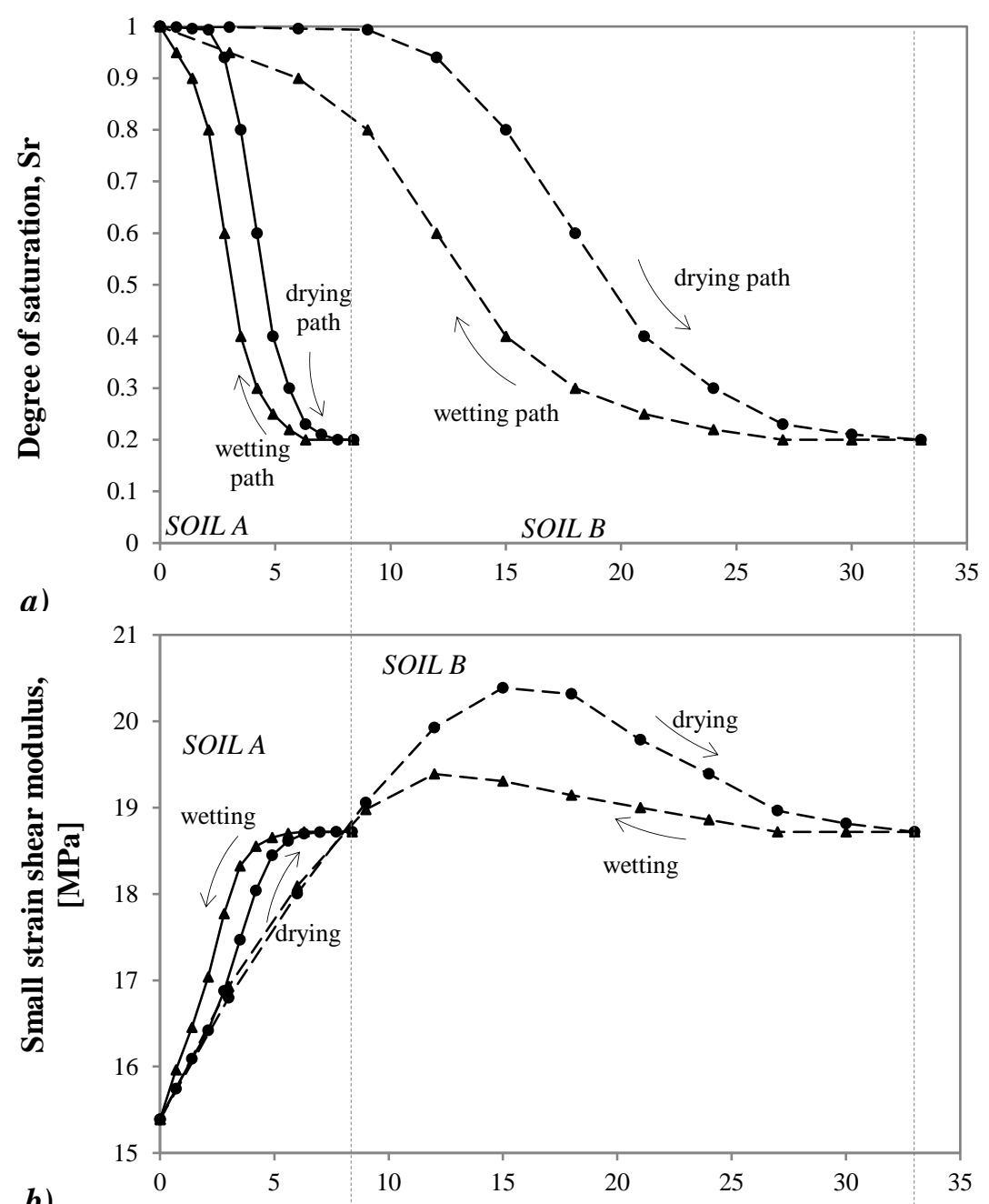

b)

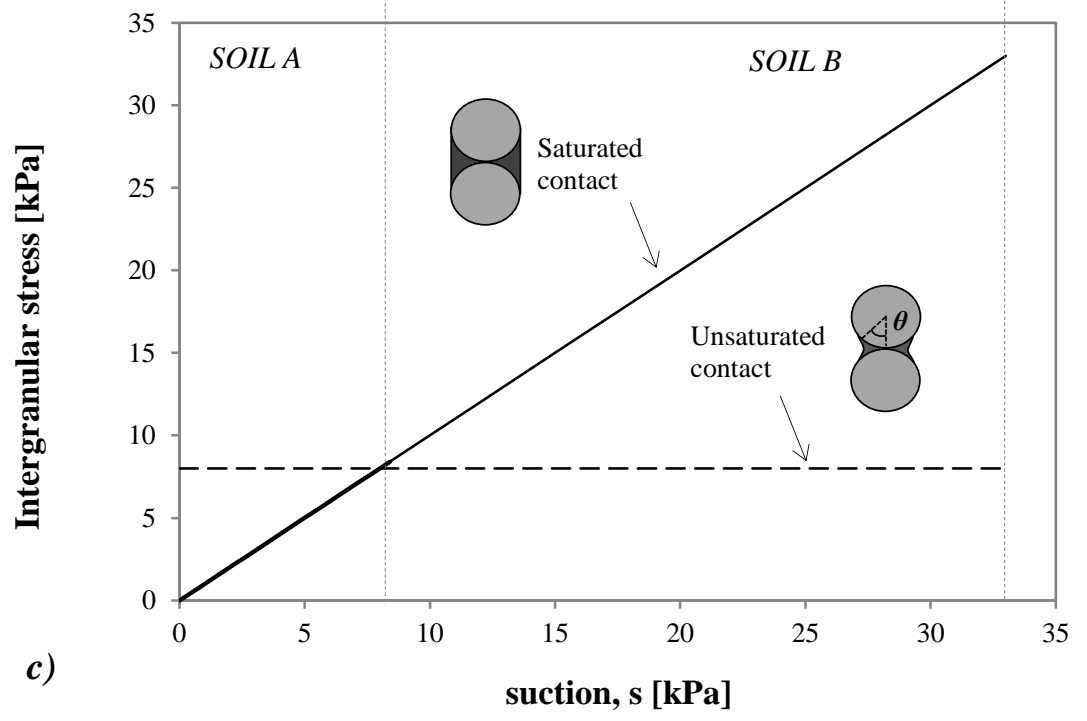








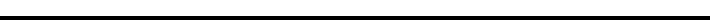



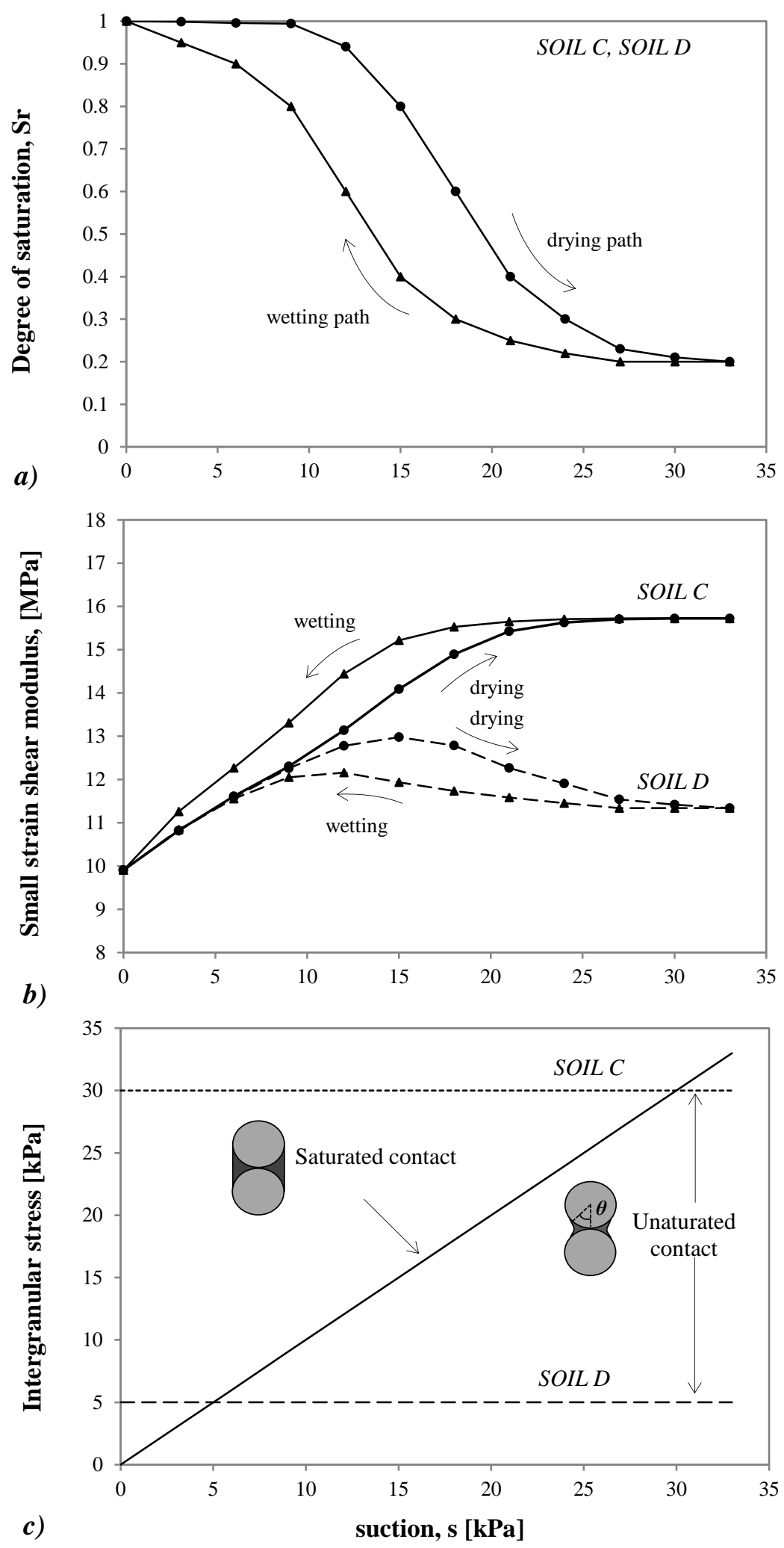







\begin{tabular}{|ccc|}
\hline \multicolumn{3}{|c|}{ Specimen } \\
\hline Height, $\boldsymbol{h}$ & 12.5 & $\mathbf{c m}$ \\
Diameter, $\boldsymbol{D}$ & 10.0 & $\mathbf{c m}$ \\
Total volume, $\boldsymbol{V}_{\text {tot }}$ & 977.8 & $\mathbf{c m}^{\mathbf{3}}$ \\
Specific gravity, $\boldsymbol{G}_{\boldsymbol{s}}$ & 2.63 & - \\
Dry density, $\boldsymbol{\rho}$ & 1.59 & $\mathbf{g} / \mathbf{c m}^{\mathbf{3}}$ \\
Void ratio, $\boldsymbol{e}$ & 0.49 & - \\
Porosity, $\boldsymbol{n}$ & 0.33 & - \\
Dry mass, $\boldsymbol{M}_{\boldsymbol{d}}$ & 1554.3 & $\mathbf{g}$ \\
\hline
\end{tabular}




\begin{tabular}{|ccc|}
\hline \multicolumn{3}{|c|}{ Silt filter } \\
\hline Height, $\boldsymbol{h}$ & 1.0 & $\mathbf{c m}$ \\
Diameter, $\boldsymbol{D}$ & 10.0 & $\mathbf{c m}$ \\
Total volume, $\boldsymbol{V}_{\text {tot }}$ & 78.5 & $\mathbf{c m}^{\mathbf{3}}$ \\
Specific gravity, $\boldsymbol{G}_{\boldsymbol{s}}$ & 2.70 & - \\
Dry density, $\boldsymbol{\rho}$ & 1.25 & $\mathbf{g} / \mathbf{c m}^{\mathbf{3}}$ \\
Void ratio, $\boldsymbol{e}$ & 1.16 & - \\
Porosity, $\boldsymbol{n}$ & 0.54 & - \\
Dry mass, $\boldsymbol{M}_{\boldsymbol{d}}$ & 98.0 & $\mathbf{g}$ \\
\hline
\end{tabular}




\begin{tabular}{|c|c|}
\hline $\boldsymbol{\alpha}^{d}$ & 0.25 \\
$\boldsymbol{n}^{\boldsymbol{d}}$ & 4 \\
$\boldsymbol{\alpha}^{w}$ & 0.12 \\
$\boldsymbol{n}^{w}$ & 5.98 \\
$\boldsymbol{s}^{*}$ & -6.85 \\
\hline
\end{tabular}




\begin{tabular}{|l|c|c|}
\cline { 2 - 3 } \multicolumn{1}{c|}{} & $\begin{array}{c}\boldsymbol{k}_{\boldsymbol{n} \text { 0 }} \\
{\left[\mathrm{kN} / \mathbf{m}^{\mathbf{3} 2}\right]}\end{array}$ & $\begin{array}{c}\boldsymbol{\sigma}_{\boldsymbol{i}}^{\boldsymbol{m}} \\
{[\mathrm{kPa}]}\end{array}$ \\
\hline $\mathrm{SC}$ & & \\
\hline & & \\
\hline
\end{tabular}




\section{Journal Publishing Agreement}

It is our policy to ask authors to assign the copyright of articles accepted for publication to the Publisher. Exceptions are possible for reasons of national rules or funding. Please tick the relevant options below.

In assigning copyright to us, you retain all proprietary rights including patent rights, and the right to make personal (non-commercial) use of the article, subject to acknowledgement of the journal as the original source of publication.

By signing this agreement, you are confirming that you have obtained permission from any co-authors and advised them of this copyright transfer. Kindly note that copyright transfer is not applicable to authors who are opting to publish their papers as Open Access. Open Access authors retain copyright of their published paper.

Please complete the form below and include it when you submit your article online (list of websites http://www.icevirtuallibrary.com/page/authors/submitting-your-article).

Journal name:............ETOTECHNIQUE

Article title: AMICROSGALE-BASED MODEL FOR SMALISTRAIN ST FFNESS IN UNSATURATED GRANUIAR GEOMATERIALS

Manuscriptreferencenumber:...............17.......... 38

Authors: ARIANNA GEA PAGANO A.LESSAN DRO TARANTNO VANESSA MAGNANIMO

Your name: ...ARIANNA GEA PAGANO

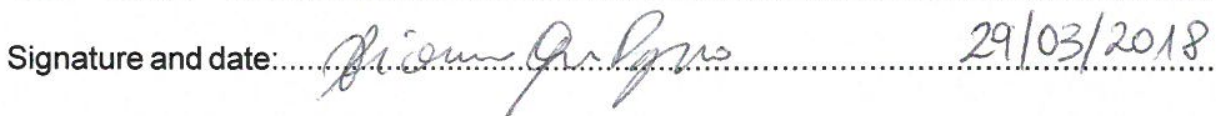

Please tick either one option from part A or one option from part B. Please complete part C.

\section{A. Copyright}

\ I hereby assign and transfer the copyright of this paper to Thomas Telford Ltd.

British Crown Copyright: I hereby assign a non-exclusive licence to publish to Thomas Telford Ltd.

I am a US Government employee: employed by (name of agency)

I am subject to the national rules of (country) ............................. and confirm that I meet their

requirements for copyright transfer or reproduction (please delete as appropriate)

B. Authors with open access funding requirements. Please specify the Creative Commons license version required.

$\square$ CC-BY (for full details click here Creative Commons Attribution (CC BY) 4.0 International License)

C. Please confirm that you have obtained permission from the original copyright holder. For ICE Publishing's copyright policy, please click here. ICE Publishing is a signatory to the STM Guidelines.

Х I have obtained permission from the original copyright holder for the use of all subsidiary material included in this paper (E.g. for borrowed figures or tables).

Thomas Telford Ltd is wholly owned by the Institution of Civil Engineers ICE Publishing, 1 Great George Street, Westminster, London, SW1P 3AA, UK Telephone: +44 (0)20 76652242 | Fax: +44 (0)20 7665 2189 | Web: www.icevirtuallibrary.com 